\section{ECONOMICS}

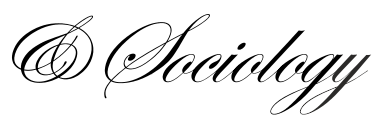

Vasilyeva, T., Ziółko, A., Kuzmenko, O., Kapinos, A., \& Humenna, Y. (2021). Impact of digitalization and the COVID-19 pandemic on the AML scenario: Data mining analysis for good governance. Economics and Sociology, 14(4), 326-354. doi:10.14254/2071-789X.2021/14-4/19

\title{
IMPACT OF DIGITALIZATION AND THE COVID-19 PANDEMIC ON THE AML SCENARIO: DATA MINING ANALYSIS FOR GOOD GOVERNANCE
}

Tetyana Vasilyeva

Sumy State University,

Sumy, Ukraine

t.vasylieva@,biem.sumdu.edu.ua

ORCID 0000-0003-0635-7978

\section{Anna Ziółko}

National Medicines Institute,

Warsaw, Poland

a.ziolko@,nil.gov.pl

ORCID 0000-0001-9530-9227

Olha Kuzmenko

Sumy State University,

Sumy, Ukraine

o.kurmenko@biem.sumdu.edu.ua

ORCID 0000-0001-8520-2266

\author{
Anna Kapinos \\ University of Technology \\ Information and Management in \\ Rzeszow, Rzeszón, Poland \\ akapinos@,wsiz.edu.pl \\ ORCID 0000-0003-2095-9481
}

\section{Yuliia Humenna \\ Sumy State University, \\ Sumy, Ukraine \\ y.bumenna@biem.sumdu.edu.ua \\ ORCID 0000-0001-5309-6016}

Received: October, 2020

1st Revision: September, 2021

Accepted: December, 2021

DOI: $10.14254 / 2071-$

789X.2021/14-4/19

JEL Classification: C4, G38, I10, O3
ABSTRACT. The article deals with the impact of digitalization and COVID-19 on the choice of AML scenarios for reforming the system of tactical and strategic monitoring of transactions carried out by economic entities based on providing good governance. The study period is 2011-2020; the objects of the study are 140 countries. Calculations are performed using Data-Mining methods, such as AML scenarios based on the classification tree method (one-dimensional CART branching method) and clustering of countries according to relevant AML scenarios based on agglomerative methods. There are three stages of research. The first builds a comprehensive system of indicators which involves financial inclusion indicators of the population, the ranking of countries on the Basel AML Index, and effectiveness of the AML policy implementation at the country level. The second stage considers countries' clustering according to the AML scenarios and formalizes the portraits of countries' clusters. The third stage examines the impact of digitalization and COVID-19 on the choice of AML scenarios. According to the empirical results, rapid, moderately rapid, slow and neutral adaptability to external factors are formalized in the possible scenarios as a result of such effects. Moreover, the countries' clustering proves that the money laundering risks relevant to the country lower and the implementation of the AML measures by the state grows more effective with higher financial inclusion for the population in the country. The study results can be helpful for authorized bodies in providing good governance while conducting financial monitoring and analysis of information on transactions carried out by economic entities.
Keywords: digitalization, COVID-19, good governance, AML policy, financial inclusion, clustering, Basel AML Index. 


\section{Introduction}

The rapid development of digitalization processes has penetrated all spheres of social and economic life during Covid-19. It became a trigger for shifting the emphasis towards the creation of organizational, economic, and practical mechanisms for regulation of the financial processes in countries, namely Anti-Money Laundering (AML) policy implemented by the state. Thus, the country's socio-economic growth indicators are significantly affected by the macroeconomic instability levers, among which the volume of the informal (shadow) economy takes priority. The implementation of an effective and consistent anti-corruption policy aimed at providing good governance will reduce and avoid economic and financial risks and will help increase socio-economic development indicators of the country.

Financial Action Task Force (FATF) is an inter-governmental institution providing international standards aimed at preventing such illegal activities as money laundering and terrorist financing. According to its standards, the growth of financial inclusion indicators of the population, that is access to the capital among the population, will increase the effectiveness of the AML measures in the countries, and respectively decrease economic and financial risks. Thus, if the financially excluded or underserved people, in particular those with low income or living in a rural sector or without documents, are provided with access to regulated financial services, the implementation of AML measures will be strengthened.

Trends and nature of the citizens' financial inclusion indicators have been affected by the global digital transformation and the consequences of Covid-19. Thus, the general trend for the population in the social context has been an increase in the number of consumers of digital services: they almost doubled in the last seven years and in 2021 this figure was 2.14 billion consumers (Statista, 2021). During 2015-2019, the level of society's readiness to implement Fintech services in everyday life increased significantly. The consumer fintech adoption indicator reflects that: from $18 \%$ to $75 \%$ - when implementing money transfer and / or payment service; from $8 \%$ to $48 \%$ - when using insurance services (insurtech); from $17 \%$ to $34 \%$ - with the accumulation of savings and investments; from $6 \%$ to $27 \%$ - when making borrowings (Statista, 2021). One should note that the Covid-19 pandemic has a significant impact on society's behavior in terms of financial resources. More than $30 \%$ of the population in such countries as Hong Kong, France, Indonesia, China, and India in the post-pandemic period in 2020 is characterized by significant savings, while in Mexico, the United Arab Emirates and India, almost $20 \%$ of the population were forced to apply to loans to restore the difficult financial situation caused by the pandemic outbreak (Statista, 2021). In 2020, there was a high share of digital population using online banking services. Italy was the leading country in terms of the digital population using information and communication technologies related to the use of banking services in 2020 (86.8\%). The United Kingdom took the second position (84.3\%), Spain - the third (82.8\%) (Statista, 2021).

Thus, given the current global trends within the impact of pandemics and digitalization on indicators of socio-economic development, in particular on indicators of financial inclusion of the population, which in turn affects the AML policy effectiveness, it is necessary to analyze possible changes in AML scenarios for reforming the system of tactical and strategic monitoring of transactions carried out by economic entities and based on good governance.

In this study, based on the practical findings and reports of the above-mentioned intergovernmental institution FATF, each country's implement the appropriate AML scenario considering the chain of such relationships: the growth of financial inclusion of the population contributes to the effectiveness of AML measures while implementing the AML policy, that in turn minimizes economic and financial risks, particularly in the shadow sector. Such risks 
will be analyzed based on data on the ranking of the world according to the Basel AML Index.

The purpose of this study is to find the impact of such global triggers as digitalization and pandemic on the AML policy implementation by public authorities and financial monitoring, in the context of good governance, considering changes in financial inclusion indicators as primary levers of impact and risks of shadow economic sector - as the result indicators of implementing the AML measures.

The study directs on formalizing AML scenarios for each country according to the country's cluster affiliation based on AML policy effectiveness within countries, financial inclusion indicators and Basel AML Index, followed by determining the impact of digitalization and COVID-19 on implementing the AML scenarios in terms of existing or new cluster (in case of transition to it).

The paper consists of three chapters. The first chapter deals with the literature review. The second section describes the research methods of the study. The third chapter demonstrates the empirical results of the investigation. The conclusion section and references complete the paper.

\section{Literature review}

In the framework of the study, it is important to analyze the relationship between information and communication technologies (ICT), pandemic effects, on the one hand, and shadow economy indicators, in particular in terms of the impact on its AML policy, - on the other. To start with digitalization impact, Adam \& Fazekas (2021) made indisputable scientific contribution in this direction. This study examines the arguments for the effectiveness of ICT as a lever in the fight against corruption. The study is based on a thorough and in-depth literary analysis, which focuses on 30 scientific papers regarding the impact of ICT tools (digital public services, crowdsourcing platforms, whistleblowing tools, transparency portals, distributed ledger technology, artificial intelligence) on corruption. Methodological support of the analyzed scientific works includes a wide range of economic and mathematical methods (regression analysis, case study, descriptive statistics, peer reviewed expert survey, self-assessment, secondary data analysis, automated website checks and others); samples vary from one country to a global scale. The study results confirm that based on the common features of ICT technologies, the latter can serve as a tool to combat corruption schemes by influencing public scrutiny in the following ways: reporting on corruption, ensuring transparency of such reporting, adjusting the interaction between citizens and the government. Negative manifestations of ICT for the informal economic sector are the functioning of cryptocurrencies, the abuse of centralized databases. The implementation of ICT tools in practice does not automatically reduce the volume of corrupt transactions, but rather depends on the relevance of the digital technology used to the features of conditions, needs, cultural and technological experience of each country, respectively.

In contrast to the previous study, Setor, et al. (2021) investigated and confirmed in their work the one-sided nature of the digitalization impact, in particular positive effect, on corruption. Based on fixed-effects analysis for 111 developing countries, for the period from 2010 till 2018 scientists found out that the implementation of digital payments reduces the corruption in the developing countries.

Many scientific publications have been devoted to determining the relationship between information and communication systems (ICS) and the effectiveness of anticorruption measures by public authorities. The study of Leonov et al. (2019) proved that the ICS in the banking sector during financial monitoring would reduce reputational risks, 
minimize losses and improve the quality and efficiency of customer's inspections by equalizing the human factor with the maximum detection speed of suspicious transactions.

The studies of Syniavska et al. (2019), Gasparènienè et al. (2017), Acemoglu et al. (2004) deal with the impact and interaction of digitalization and the shadow economy, in terms of the anti-corruption policy in various areas of financial intermediaries' regulation. One should note the study of Syniavska et al. (2019), which formed a model reflecting the process of combating fraud in the electronic banking sector, is based on the Lotka-Volterra classic model with logistical growth and dynamic Holling-Tanner models.

Numerous studies deal with the analysis of the digitalization impact on the functioning of financial markets, in particular, determining the impact of financial technologies on capital markets (Paskevicius \& Keliuotyte-Staniuleniene, 2018), assessing the digitalization of financial services (Pakhnenko et al., 2021), studying the features of e-banking (Alam et al., 2021), analysis of prospects for investing-sustainable and responsible investing in the digital age (Formankova et al., 2018).

It is necessary to analyze the studies of shadow economy to investigate the impact of digital process and pandemic on the the countries' AML policy. Some aspects of the factors, nature and causes of the money laundering processes, as well as the need for effective AML policy by the government have been studied in the works of Tiutiunyk et al. (2018), Lyeonov et al. (2020), Kuzmenko et al. (2020), Zolkover \& Terziev (2020). The peculiarities of risk assessment of suspicious transactions made by insurance companies were investigated respectively by Boyko \& Roienko (2014), evaluation of insurance companies' indicators - by Kozmenko \& Roienko (2013).

The impact of shadowing on social, economic and financial indicators of the countries' functioning and growth is widely studied in the scientific works of (Oliinyk et al., 2019; Brychko et al., 2021). The key role of the informal sector of economy for the social development of the countries was grounded in the research (Mishchuk et al. 2020). The government's oversight of shadow transactions in public governance had a positive impact on countries' economic development, as evidenced by a descriptive research design for the Gulf Cooperation Council from 1996 to 2019 made by Al-Naser \& Hamdan, (2021). Based on the study of Simovic (2021), scientists have confirmed the inversely proportional impact of corruption on economic growth by building an econometric model for determining the impact of the corruption perception index on gross domestic product in terms of Southeast Europe in 2003-2018. The decisive influence of shadow processes on financial indicators of countries' development, in particular issues of financial and economic security, - has been confirmed in the study headed by Shpak et al. (2021).

Furthermore, nowadays, the relationship between shadow economy and countries' ecological indicators is discussed. Thus, scientists headed by Bilan et al. (2020a) based on the forming the cointegration equations of the GDP carbon intensity dependence on the macroeconomic factors confirm great impact on the indicator made by taxes, public investments and shadow economy. Chigrin \& Pimonenko (2014) discussed the peculiarities of the financial resources attraction due to ecological securities issues.

Special attention should be paid to the accelerated development of ICT and digital innovations, the promotion of non-cash payments in the context of the Covid-19 pandemic in studies of Civelek et al. (2021), Sawangchai et al. (2020), Bilan et al. (2020b), etc.

Many research deal with the impact of the Covid-19 pandemic on the daily public lives (Tomcikova et al. 2021; Chmielecki, 2021; Kolosok \& Jakubowska 2020), economic indicators of countries' growth (Tiutiunyk et al., 2021a; Mishenina et al. 2021; Przytuła et al. 2020; Liu et al. 2021; Dementiev, 2021; Polinkevych et al. 2021), social issues (Kadar \& Reicher, 2020; Stefan et al. 2020) and financial issues of development (Hinrichs \& Bundtzen, 2021; Pardal et al. 2020). So, the studies on the relationship between the pandemic effects and 
socio-economic indicators of the countries' development are widely presented in numerous scientific publications. Within the framework of the conducted research, Smiianov et al. (2020) hypothesized that there is a relationship between pandemic lockdown and social, economic and environmental development indicators. Based on the system dynamics analysis and Vensim software, the negative impact of the quarantine on the country's economic, social and environmental growth was confirmed. At the same time, if the government lifts the quarantine, the reduction in GDP growth will be higher, and the level of those infected with the growing disease will be the highest, i.e., the government must ensure a quarantine regime and strengthen control over its observance.

Unlike the previous analysed research, which highlights the relationship between individual components and socio-economic development indicators, the works of Stukalo et al. (2021), Trifu (2020), Stukalo et al. (2020), Androniceanu (2020) substantiate the necessity to consider global threats in determining the organizational and economic mechanisms for regulating socio-economic and financial processes in the country, in particular by public authorities. Thus, in the work of Stukalo et al. (2021), scientists have substantiated the creation of a new governance mechanism, including a new form of government, a new format of public relations and a new economic model to increase the stability of the national economy to global threats, including the most dangerous rates of morbidity, high infant mortality, corruption, low energy security and inefficient state administration.

Based on open data accumulated by the FATF from member countries of the FATF and FATF-style regional bodies (FSRBs) and such global observer organizations as the International Monetary Fund (IMF), the World Bank and the United Nations, key threats to the impact of Covid-19 on the global anti-money laundering measures are the increased fraud, including impersonation of officials, counterfeiting, including essential goods (such as medical supplies and medicines), fundraising for fake charities, fraudulent investment scams; Cyber Crime, including Email and SMS phishing attacks, business email compromise scams, ransomware attacks; impact on other predicate crimes, which include human trafficking and exploitation of workers, online child exploitation, organized property crime. The contextual factors and money laundering vulnerabilities of the pandemic impact on the AML measures effectiveness by FATF include: 1) as a result of the economic crisis - a change in the financial behaviour of the population, forced to turn to unofficial sources of funding (triggers of such changes are increased remote transactions, unfamiliarity with online platforms, unregulated financial services); 2) misdirection of state financial support or international financial assistance and increased risks of corruption within these processes; 3) increased levels of financial and economic volatility as a result of the pandemic, which led to the emergence of new vulnerable zones - domestic trade, economic downturn and increased physical cash transactions (FATF, 2021).

The study of the impact of digitalization and pandemic processes on the implementation of AML policy and the further AML development scenarios in the study is based on indicators of financial inclusion of the population. The additional analysis requires scientific research in this area. Many scholars have highlighted the relationship between financial inclusion, on the one hand, and social, economic, and financial indices, on the other (Didenko et al., 2020; Didenko \& Sidelnyk, 2021; Dr. Man Bahadur BK \& Bhandari, 2021; Saraswati et al., 2020). Researchers headed by Didenko within the study (Didenko et al., 2020) substantiated the relationship between financial inclusion and the social security through the determination of the socio-safety Index based on the principal component method. Analyzing the economic development indicators of 26 countries, ten indicators for behavioural aspects of financial inclusion and eight indicators of social security, the study of Didenko et al. (2020) confirms the statistically significant relationship between social security index and such financial inclusion indices as using the Internet to pay bills or make online 
purchases, and respondents' number who have credit cards. In the context of the study of changes in the financial inclusion indicators of the population as a result of the pandemic impact, an increase in opportunities for society in access to financial resources was revealed.

Dr. Man Bahadur BK \& Bhandari in the study (Dr. Man Bahadur BK \& Bhandari, 2021) insisted that financial inclusion is not only a social priority for governments, but also a precondition for business growth. Providing the financial inclusion for the population according to scientists can be an innovative direction in expanding the market, growing the customer base, stimulating the mass market, and thus - improving the welfare of the whole nation.

According to Saraswati et al. (2020), scientists focus on the ambiguous nature of the impact made by modern digital financial technology on the financial inclusion of society. On the one hand, the development of fintech can significantly increase financial inclusion by expanding access to financial services for citizens. On the other hand, digitalization changes the structure of the payment system and affects the effectiveness of monetary policy in the country. The results of the study to determine the effects of fintech and financial inclusion on the effectiveness of Indonesian monetary policy, for the period from 2009 to 2018 based on the Vector Error Correction, showed that financial inclusion affects inflation as an indicator of monetary policy effectiveness in the short and long run, so government policies need to be well-balanced and consistent to ensure price stabilization by increasing the financial inclusion of citizens; shocks in the implementation of financial innovations have a significant impact on inflation only in the short term, while volatility - on a permanent basis due to the substitution effect and the cost of capital effect.

Features of the digitalization impact on the countries' socio-economic development indicators besides the aspects of financial inclusion were investigated in many studies. Thus, ICT effects on economic issues were developed in the following research. Tiutiunyk et al. (2021b) - cross-country and macroeconomic analysis on the assessment of the impact of digital transformation on macroeconomic stability for EU countries; Petroye et al. (2020) effects of information security on the country's image; Małkowska et al. (2021) - on the digitalization of society, digitalization of economy and business digitalization; Petrushenko et al. (2018) - the research, related with business activity regarding the role of FinTech companies in the system of crossborder money transfers in Ukraine. Danarahmanto et al. (2020) consider developing the digital start-up company based on customer participation and innovations; Gallo et al. (2019) - peculiarities of innovative trends in human resources management of the companies. Challenges and business risks were developed in the study of Yarovenko et al. (2021) about the assessing the risks of information and knowledge loss management, within the investigation carried out by Kobushko et al. (2021) on aspects of cash management.

The link between digitalization and indicators of countries' social development is evidenced in many scientific works. Thus, based on a study of indicators of digital development of the European Union and the United Kingdom using partial least squares structural equation model scientists Lamberti et al. (2021) confirmed the role of education as the primary lever of digital inequality among the population and the level of digital development of the country - as a crucial lever for vulnerable groups, that is socially disadvantaged Europeans have more benefits to live in countries with high digitalisation.

In the study by Matarazzo et al. (2021) based on the method of multi-case study in the context of six small and medium enterprises, scientists have developed that the impact of digital transformation forms the preconditions for customer value creation. Thus, the authors found that the use of digital tools contributes to the introduction of innovations in the business model, the formation of new distribution channels and new ways to provide value to the customer base. 
Significant research on social aspects of countries' growth under the influence of digital technologies were analysed as follows: on digital learning for adults by Petrushenko et al. (2021) and actual problems of finance teaching by Lyeonov \& Liuta (2016), on detecting cyber threats through social network by Kirichenko et al. (2017), on interrelations between the real man, his digital individual and the market of the digital economy by Beyi (2018), on socio-economic challenges of blockchain technology implementing by Lopez et al. (2019).

\section{Research methods}

Conducting the study involves the data set of indicators, which characterize financial inclusion of the population, the ranking of countries according to the Basel AML Index, AML policy effectiveness at the country level and effects of digitalization and Covid-19 on the country's development. The period of the study is 2011-2020. The objects of the study are 140 countries.

The information base for the accumulating the information on the above indicators includes data about indicators on Covid-19 in terms of countries from the World Health Organization (2021), data on indicators of digital development trends affected by the Covid19 situation relevantly by country - from Business Data Platform - Statista (2021), data from web-site on International Digital Economy and Society Index (I-DESI, 2021) and data about AML policy effectiveness - from the website of FATF (2021).

The study is implemented in three stages using Data-Mining methods. The first stage involves the construction of a comprehensive set of indicators for the further calculations. Thus, the input statistical base of the study formed at this stage has the following groups of indicators:

1 group - indicators of the AML policy effectiveness;

2 group - Basel AML Index Score;

3 group - indicators of the financial inclusion.

The first group includes the indicators of the AML policy effectiveness which according to FATF (2013) are presented by immediate outcomes (IO), reflecting the key objectives to which the AML activities are aimed:

IO1 - Money laundering and terrorist financing risks are understood and, where appropriate, actions co-ordinated domestically to combat money laundering and the financing of terrorism and proliferation,

IO2 - International co-operation delivers appropriate information, financial intelligence, and evidence, and facilitates action against criminals and their assets,

IO3 - Supervisors appropriately supervise, monitor and regulate financial institutions and DNFBPs for compliance with AML/CFT requirements commensurate with their risks,

IO4 - Financial institutions and DNFBPs adequately apply AML/CFT preventive measures commensurate with their risks, and report suspicious transactions,

IO5 - Legal persons and arrangements are prevented from misuse for money laundering or terrorist financing, and information on their beneficial ownership is available to competent authorities without impediments,

IO6 - Financial intelligence and all other relevant information are appropriately used by competent authorities for money laundering and terrorist financing investigations,

IO7 - Money laundering offences and activities are investigated, and offenders are prosecuted and subject to effective, proportionate and dissuasive sanctions.

These seven indicators are IEAML1, IEAML2, IEAML3, IEAML4, IEAML5, IEAML6, IEAML7. The scale of values of these indicators is as follows:

0,25 - low level of AML policy effectiveness that means the immediate outcome is not achieved or achieved to a negligible extent, fundamental improvements needed; 
0,5 - moderate level of AML policy effectiveness that means the immediate outcome is achieved to some extent, major improvements are required.

0,75 - substantial level of AML policy effectiveness that means the immediate outcome is achieved to a large extent; moderate improvements are required.

1,0 - high level of AML policy effectiveness that means the immediate outcome is achieved to a very large extent, minor improvements are required.

The second group describes AML Index (Basel Institute on Governance, 2021) in terms of the countries, represented by Basel AML Index Score (if score is 8 the risk is high and if 1 - the risk is low). The Basel AML Index as the independent annual ranking provides assessing of money laundering and terrorist financing (ML/TF) risks within the countries. The risks scores provide the information according five directions that are: 1) Quality of ML/TF Framework; 2) Bribery and Corruption; 3) Financial Transparency and Standards; 4) Public Transparency and Accountability; 5) Legal and Political Risks.

The indicators of the first and second groups, selected due to the trends and features of AML measures by country (Group 2 - Basel AML Index Score), describe the effectiveness of such measures by the state (1 group of indicators) according to Methodology for assessing technical compliance with the FATF recommendations and the effectiveness of AML/CFT system (FATF, 2013).

The third group of indicators is represented by ninety-eight indicators of financial inclusion. The accumulation of data on financial inclusion in this study considers implementing the Demand-Side approach (IMF, 2021), which involves collecting information from households and economic entities on the use of financial services based on the inquiry results. The use of the Demand-Side method will allow make the most socially oriented emphasis on indicators of the financial services thanks to the accumulation of the information on interrogation results from the population, instead of financial intermediaries within the Supply-Side approach. Indicators of financial inclusion for the population, in terms of such criteria as: income level, employment, living outside the city, - characterize the following forms of financial service availability: opening an account, in particular in a financial institution; the amount of savings; the amount of unpaid mortgage; loan to start a business.

In the first stage of the research to determine the priority of 98 financial inclusion indicators that means defining the feasibility of including indicators in empirical calculations the authors conducted a study based on the principal component analysis (PCA). PCA-method is one of the main methods in economic practice to reduce the dimensionality of data by losing the least amount of information (PCA, 2021). Using in our study PCA-method consider data compression of general amount of financial inclusion indicators (98 indicators). The main components method is implemented in the article using the Statistica software package the command Statistics / Multivariate Exploratory Techniques / Principal Components and Classification Analysis.

While determining the priority financial inclusion indicators, the general set of financial inclusion indicators is analyzed in the study. It characterizes the following financial services: access to opening (availability) an account, in particular in a financial institution; the amount of savings; the amount of outstanding housing loan; loan to start a business - in terms of such criteria as income level, employment, living rural.

The second stage of the study is directed on formalizing AML scenarios for each country according to the country's cluster affiliation based on indicators of AML policy effectiveness within countries, financial inclusion indicators and Basel AML Index consider several steps:

- clustering the countries according to the AML scenarios based on analysis of financial inclusion indicators, indicators of AML policy effectiveness and directly Basel AML Index Scores within countries; 
- formalizing the portraits of countries' clusters taking into account both simultaneous and separate consideration of relevant financial inclusion indicators, ranking of countries on the Basel AML Index Score, and indicators of AML policy effectiveness at the country level.

While clustering the countries around the world by relevant AML scenarios the agglomerative methods of minimum variance (iterative divisive method of k-means and tree clustering) are used in the study (Maynard, 2021). That approach allows divide the countries into groups (clusters) under the conditions of their similar features within three groups of indicators that characterize financial inclusion, efficiency of AML policy and Basel AML Index. There is a need to justify the number of proposed groups (clusters) based on the variance analysis to find the number of clusters.

During the practical clustering of countries in the study, it is proposed to use the variance analysis results to evaluate and further compare different numbers of clusters in the study.

The following criteria prove the quality of this clustering:

- minimization of the intragroup variance and maximization of intergroup variance. Fulfillment of this criterion confirms the quality of the traits in terms of each indicator of the countries' belonging degree to the relevant cluster and - the clustering quality;

- maximization of the Fisher criterion $(F)$ and the direction of the probability of the null hypothesis deviation (p) to the zero value, namely the inexpediency to use a relevant indicator for describing the countries' belonging degree to the cluster.

The affiliation of countries to each cluster in the study is proposed to determine based on k-means method (within using the agglomerative methods). In the context of using the kmeans method in terms of the initial centers of clusters, the authors propose to choose the distance sorting and selection of observations at constant intervals. Calculations based on the k-means method consider the following quantitative features: averages for each cluster (averaging is performed within the cluster), Euclidean distances (Euclidean metrics) and squares of Euclidean distances between clusters.

When clustering countries according to the scenarios for reforming the system of tactical and strategic monitoring of transactions carried out by economic entities, the next step within the second stage is to formalize the portraits of countries' clusters based on the onedimensional branching CART method within classification trees. It is a method to predict the affiliation of objects (countries) to the corresponding class of categorical variable (cluster 1, 2, 3 or 4) depending on the values of one or more independent input predictors. The role of predictors is played by the financial inclusion indicators, indicators of the effectiveness of AML policy and the Basel AML Index Score within countries.

Classification trees, widely used in economic studies for predictive modeling of the target variable based on several variables at the input (Song, Y., \& Lu, Y., 2015; Vala, K., 2019), consider the constructing process. It involves the implementation of four steps:

1. the procedure for selecting the forecast accuracy criteria based on equal prior probability method.

2. the procedure for selecting branching options based on the activation of the CART method, namely the classification tree program, which, when building a tree, performs a complete search of all possible options for one-dimensional branching. The Gini index, the sum of all pairwise products of the relative class sizes represented at the considered top of the trees, was chosen as the consistency criterion. Ginny index values will be maximum if all classes are the same size.

3. detection of the moment at which it is necessary to stop the branching procedure based on the selected direct stop of the branching procedure by the FACT method. The branching method by predictor variables continues until each terminal vertex contains no one incorrectly classified object (country). 
4. determination of the required size for the classification tree by the global crosschecking method, when the number of iterations is set by default to three.

We will build portraits of countries' clusters using the classification tree method in terms of four projections: both simultaneous and separate consideration of relevant financial inclusion indicators, ranking of countries on the Basel AML Index Score, and indicators of AML policy effectiveness at the country level. The emphasis will be placed on each of the 3 groups of input indicators separately.

The third stage of the study considers determining the impact of digitalization and COVID-19 on the implementation of AML scenarios in terms of current or new cluster (in case of transition to it). Methodical basis for the implementation of this task is the same as during the second stage of the study realization: re-grouping the countries into four clusters by expansion the list of financial inclusion indicators, AML effectiveness indicators and AML index with the indicators characterizing the impact of COVID-19 and digitization (with the agglomerative methods of minimum variance); formalizing the portraits of countries' clusters under the impact of the global triggers (with the one-dimensional branching method CART within classification trees).

The study of the COVID-19 and digitization effects on economic indicators, in particular in terms of AML scenarios, is based on the analysis of the following indicators:

- indicators of the pandemic impact (ICCOVID1 - COVID-19 Cases, cumulative total; ICCOVID2 - Deaths, cumulative total);

- indicators characterizing the use of e-commerce products by the population before the pandemic (ICCOVID3 - Change in e-commerce usage to purchase products normally bought in-store due to coronavirus worldwide as of March 15, 2020, by country, prepandemic period, \% ), during the coronavirus announcement in early 2020 (ICCOVID7 Share of consumers that shopped online for the first time since the coronavirus pandemic was declared in 2020,\%), during the pandemic peak (ICCOVID4 - Change in e-commerce usage to purchase products normally bought in-store due to coronavirus worldwide as of March 15, 2020 , by country, peak of pandemic, \%), in modern conditions as a result of pandemic and quarantine measures (ICCOVID5 - Change in e-commerce usage to purchase products normally bought in-store due to coronavirus worldwide as of March 15, 2020, by country, current, \%);

- normalized scores of the International Digital Economy and Society Index (I-DESI) for each country, respectively (ICCOVID6)).

These indicators in the investigation are chosen due to the following arguments: the selected indicators of the impact made by COVID-19 (ICCOVID1 and ICCOVID2) describe the current state of the recorded cases of COVID-19 morbidity and mortality; indicators of the pandemic impact on the population's preferences in use the means of e-commerce (ICCOVID3, ICCOVID4, ICCOVID5 and ICCOVID7) allow to consider the pandemic role as a trigger to accelerate digitalization among the population; the indicator ICCOVID6, which characterizes trends of I-DESI within countries provides information on the cross-country situation regarding digital technologies and the implementation of digital transformation in the social and economic spheres of society.

Based on the empirical research at this stage, we could determine the impact of digitalization and COVID-19 on the implementation of AML scenarios in terms of the current or new cluster (in case of transition to it). Thus, depending on the countries' adaptability (response) to the effects of digitalization and COVID-19, the following AML-scenarios would be defined:

- AML-scenario of neutral adaptability that means the country has not changed the cluster under the influence of digitalization and COVID-19; 
- AML-scenario of slow adaptability that means the country would be shifted within clusters by one position (one cluster) under the influence of digitalization and COVID-19;

- AML-scenario of moderately rapid adaptability where the country would be shifted by two positions (two clusters);

AML-scenario of rapid adaptability when the country would be shifted by three positions (three clusters) under the digitalization and COVID-19 impact.

The practical implementation of the study task within three stages, in particular, defining priority financial inclusion indicators with principal component method at the first stage; estimating the number of clusters based on the variance analysis, countries' clustering by using agglomerative methods of minimal variance, formation of countries' portraits by using the classification trees - at the second and third stages, - is carried out with methodological tools based on the software product Statistica 8.

\section{Conducting research and results}

\subsection{Prioritization of financial inclusion indicators}

When finding priority indicators of financial inclusion based on the use of the principal component method, the construction of a correlation matrix is assumed. The eigenvalues of the correlation matrix and related statistics in Table 1 enable to state that at least 75\% (79.98\% - accumulated impact, column "Cumulative" in Table 1) of variations provide the first five main components. It means that it is reasonable to consider the first five factors to select the most priority indicators of financial inclusion.

Table 1. The eigenvalues fragments in the correlation matrix while the selection the financial inclusion indicators priority

\begin{tabular}{|c|c|c|c|c|}
\hline \multirow{2}{*}{ Value number } & \multicolumn{4}{|c|}{$\begin{array}{l}\text { Eigenvalues of correlation matrix, and related statistics (IFI.sta) } \\
\text { Active variables only }\end{array}$} \\
\hline & Eigenvalue & $\begin{array}{l}\% \text { Total } \\
\text { variance }\end{array}$ & $\begin{array}{l}\text { Cumulative } \\
\text { Eigenvalue }\end{array}$ & $\begin{array}{c}\text { Cumulative } \\
\%\end{array}$ \\
\hline 1 & 34,30500 & 38,11667 & 34,30500 & 38,1167 \\
\hline 2 & 16,19686 & 17,99651 & 50,50186 & 56,1132 \\
\hline 3 & 11,11975 & 12,35528 & 61,62161 & 68,4685 \\
\hline 4 & 5,81394 & 6,45993 & 67,43555 & 74,9284 \\
\hline 5 & 4,54654 & 5,05171 & 71,98209 & 79,9801 \\
\hline 6 & 3,26457 & 3,62730 & 75,24666 & 83,6074 \\
\hline 7 & 2,39788 & 2,66431 & 77,64454 & 86,2717 \\
\hline 8 & 1,79784 & 1,99760 & 79,44238 & 88,2693 \\
\hline 9 & 1,68666 & 1,87407 & 81,12905 & 90,1434 \\
\hline 10 & 1,46242 & 1,62492 & 82,59147 & 91,7683 \\
\hline
\end{tabular}

Source: own compilation

Therefore, to determine the priority of financial inclusion indicators, we consider the total variation percentage provided by the first five factors and the contribution of financial inclusion indicators based on correlation (Table 2), in terms of these factors, which we will form in a single impact assessment based on arithmetic weighted mean. 
Table 2. Analysis of the contribution of financial inclusion indicators by main components

\begin{tabular}{cccccc}
\hline \multirow{2}{*}{ Variable } & \multicolumn{5}{c}{ Variable contributions, based on correlations (IFI.sta) } \\
& Factor 1 & Factor 2 & Factor 3 & Factor 4 & Factor 5 \\
\cline { 2 - 6 } & 0,019304 & 0,001798 & 0,021612 & 0,005833 & 0,000083 \\
\hline IF11 & 0,018816 & 0,001107 & 0,018054 & 0,008184 & 0,000637 \\
\hline IFI4 & 0,018245 & 0,002358 & 0,023223 & 0,003769 & 0,000026 \\
\hline IFI5 & 0,019031 & 0,001211 & 0,019719 & 0,005851 & 0,000277 \\
\hline IFI6 & 0,019441 & 0,002381 & 0,020717 & 0,005173 & 0,000047 \\
\hline IFI7 & 0,018161 & 0,007049 & 0,009950 & 0,003348 & 0,000939 \\
\hline IFI8 & 0,018955 & 0,001388 & 0,017308 & 0,007950 & 0,000563 \\
\hline IF110 & 0,018347 & 0,003214 & 0,022211 & 0,002968 & 0,000061 \\
\hline IF111 & 0,019171 & 0,001621 & 0,019106 & 0,005331 & 0,000188 \\
\hline IF112 & 0,024051 & 0,006077 & 0,000016 & 0,000099 & 0,000351 \\
\hline IF144 & 0,021628 & 0,008303 & 0,000603 & 0,002122 & 0,004209 \\
\hline IF146 & 0,023615 & 0,005392 & 0,000008 & 0,000605 & 0,000000 \\
\hline IF147 & 0,000991 & 0,048777 & 0,000879 & 0,000420 & 0,007649 \\
\hline IF150 & 0,001173 & 0,049214 & 0,000263 & 0,000036 & 0,007192 \\
\hline IF151 & 0,012795 & 0,025231 & 0,001869 & 0,000002 & 0,001663 \\
\hline IF156 & 0,011069 & 0,006844 & 0,037381 & 0,003118 & 0,006246 \\
\hline IF162 & 0,009861 & 0,010007 & 0,036672 & 0,001585 & 0,004450 \\
\hline IF163 & 0,009354 & 0,006450 & 0,039500 & 0,000185 & 0,007555 \\
\hline IF165 & 0,010908 & 0,006120 & 0,029907 & 0,007955 & 0,004342 \\
\hline IF166 & 0,009791 & 0,004571 & 0,042333 & 0,000720 & 0,005042 \\
\hline IF167 & 0,018383 & 0,002765 & 0,016938 & 0,000544 & 0,001584 \\
\hline IF168 & 0,005892 & 0,009010 & 0,007573 & 0,010926 & 0,100631 \\
\hline IF174 & 0,004479 & 0,010180 & 0,008124 & 0,004400 & 0,103328 \\
\hline IF175 & 0,006173 & 0,008453 & 0,006246 & 0,008860 & 0,102313 \\
\hline IF179 & 0,011069 & 0,006844 & 0,037381 & 0,003118 & 0,006246 \\
\hline IF180 & 0,009861 & 0,010007 & 0,036672 & 0,001585 & 0,004450 \\
\hline IF181 & 0,009354 & 0,006450 & 0,039500 & 0,000185 & 0,007555 \\
\hline IF183 & 0,010908 & 0,006120 & 0,029907 & 0,007955 & 0,004342 \\
\hline IF184 & 0,009791 & 0,004571 & 0,042333 & 0,000720 & 0,005042 \\
\hline IF185 & 0,002531 & 0,000109 & 0,000086 & 0,131116 & 0,008952 \\
\hline IF192 & & & & & \\
\hline & & & & \\
\hline
\end{tabular}

Financial inclusion indicators: IFI1 - Account (\% age 15+), IFI4 - Account, income, poorest 40\% (\% ages 15+), IFI5 - Account, income, richest 60\% (\% ages 15+), IFI6 - Account, rural (\% age 15+), IFI7 - Financial institution account (\% age 15+), IFI8 - Financial institution account, in labor force (\% age 15+), IFI10 - Financial institution account, income, poorest 40\% (\% age 15+), IFI11 - Financial institution account, income, richest 60\% (\% age 15+), IFI12 - Financial institution account, rural (\% age 15+), IFI44 - Saved at a financial institution (\% age 15+), IFI46 - Saved at a financial institution, out of labor force (\% age 15+), IFI47 - Saved at a financial institution, income, poorest $40 \%$ (\% age 15+), IFI50 - Saved using a savings club or a person outside the family (\% age 15+), IFI51 - Saved using a savings club or a person outside the family, in labor force (\% age 15+), IFI56 - Saved any money in the past year (\% age 15+), IFI62 - Outstanding housing loan (\% age 15+), IFI63 - Outstanding housing loan, in labor force (\% age 15+), IFI65 - Outstanding housing loan, income, poorest 40\% (\% age 15+), IFI66 - Outstanding housing loan, income, richest 60\% (\% age 15+), IFI67 - Outstanding housing loan, rural (\% age 15+), IFI68 - Debit card ownership (\% age 15+), IFI74 - Borrowed for health or medical purposes (\% age 15+), IFI75 - Borrowed for health or medical purposes, in labor force (\% age 15+), IFI79 - Borrowed for health or medical purposes, rural (\% age 15+), IFI80 - Borrowed to start, operate, or expand a farm or business (\% age 15+); IFI81 - Borrowed to start, operate, or expand a farm or business, in labor force (\% age 15+); IFI83 - Borrowed to start, operate, or expand a farm or business, income, poorest 40\% (\% age 15+); IFI84 - Borrowed to start, operate, or expand a farm or business, income, richest 60\% (\% age 15+); IFI85 - Borrowed to start, operate, or expand a farm or business, rural (\% age 15+); IFI92 - Borrowed from a financial institution or used a credit card (\% age 15+).

Source: own compilation

Based on the results of determining the financial inclusion indicators priority, we form an array of 30 relevant indicators, which can be grouped as follows:

- financial inclusion indicators which characterize the availability of accounts for population, namely the share of the population over 15 years old who have opened an account (IFI1), including income level - respectively the poorest (IFI4), and the richest (IFI5), - and living rural (IFI6);

- financial inclusion indicators which characterize the presence of an open account in a financial institution, namely the share of the population over 15 years old who opened an 
account in a financial institution (IFI7), in particular in terms of employed population (IFI8); taking into account the level of income - respectively the poorest (IFI10), and the richest (IFI11); and taking into account living rural (IFI12);

- financial inclusion indicators which characterize the population' savings, namely the percentage of the population over 15 years old who make savings in a financial institution (IFI44), in particular excluding employed (IFI46), poorest people (IFI47); savings placed in savings funds or entrusted to another person (IFI50), in particular included employed people (IFI51); savings made in the past (IFI56);

- financial inclusion indicators which characterize the amount of outstanding housing loans among population, namely - the percentage of the population over 15 years old with unpaid mortgage (IFI62), included the employed population (IFI63), the poorest people (IFI65), the richest (IFI66), and taking into account living rural people (IFI67);

- financial inclusion indicator which characterizes the ownership of the debit card by population over 15 years old (IFI68);

- financial inclusion indicators which characterize the amount of borrowings among population, namely - the percentage of the population over 15 years old borrowing for medical or health needs (IFI74), in particular for the employed population (IFI75), including living rural (IFI79); amount of borrowings for starting, running and expanding business (IFI80), included the employed population (IFI81), the poorest people (IFI83), the richest people (IFI84), taking into account living rural people (IFI85); borrowings from a financial institution or using a credit card (IFI92).

The identified at the first stage of the study priority financial inclusion indicators are the part of the comprehensive set of indicators that, along with indicators of the effectiveness of AML policy within countries and the Basel AML Index Score for different countries, form the information base for further research.

\subsection{Countries' clustering and formalizing their portraits}

Before clustering the countries by relevant AML scenarios with agglomerative methods of minimum variance the number of clusters should be grounded. Based on the variance analysis results to estimate and compare numbers of clusters in the study, the sequential selection from three to five clusters was carried out.

According to the criteria that prove the quality of the clustering and described above in the section related to methodological approach of the study, the calculations confirmed the high quality of countries' clustering in four groups (described in Table 3 where the values of intergroup (Between SS) and intragroup (Within SS) variances of traits are demonstrated).

Thus, analysis of countries' grouping into four clusters shows high values in the grouping quality in terms of financial inclusion indicator IFI56 - reducing the p-level from 0.082 to 0.016 unit fraction. Within indicator of AML policy effectiveness that is IEAML7 and such financial inclusion indicators as IFI66, IFI67, IFI68, IFI74, IFI75, IFI79, in particular, the highest level of 0.023 (which is permissible) p-value takes only for IFI67, others are much lower than 0.05 . These facts indicate the high quality of clustering in four groups of countries.

According to the same algorithm, groupings of countries into three and five groups (clusters) were analysed. Thus, the analysis of countries' grouping into three clusters confirms poor clustering, since the p-value in terms of financial inclusion indicator IFI56 exceeds the permissible level for economic research 0.05. Furthermore, for such indicators of AML policy effectiveness as IEAML7 and IEAML1, and for financial inclusion indicators related with share of people with outstanding housing loans (in particular, with high incomes, showed by index IFI66, and living rural, demonstrated by index IFI67), for people who are owners of 
debit cards (IFI68) and people who borrow money for health or medical purposes (IFI74), in particular in labour force (IFI75), living rural (IFI79), - p-value takes the maximum to acceptable level. At the same time, Fisher's criterion is not statistically significant for these indicators. The intergroup variance takes values from 0.03 to 0.25 unit fraction, while internally, group variance takes a value from 0,15 to 0,87 unit fraction. Thus, the analysis of the possibility of grouping countries into three groups shows the inadequacy of defining three clusters of the countries.

Table 3. Countries' clustering in 4 groups based on variance analysis results

\begin{tabular}{|c|c|c|c|c|c|c|}
\hline \multirow[b]{2}{*}{ Variable } & \multicolumn{6}{|c|}{ Analysis of Variance (Spreadsheet2.sta) } \\
\hline & $\begin{array}{c}\text { Between } \\
\text { SS }\end{array}$ & $\mathrm{df}$ & $\begin{array}{c}\text { Within } \\
\text { SS }\end{array}$ & $\mathrm{df}$ & $\mathrm{F}$ & $\begin{array}{c}\text { signif. } \\
\text { p }\end{array}$ \\
\hline IEAML1 & 0,65409 & 3 & 1,40729 & 52 & 8,0563 & 0,000167 \\
\hline IEAML2 & 1,14009 & 3 & 0,66348 & 52 & 29,7847 & 0,000000 \\
\hline IEAML3 & 0,52237 & 3 & 0,31691 & 52 & 28,5710 & 0,000000 \\
\hline IEAML4 & 0,38135 & 3 & 0,63205 & 52 & 10,4581 & 0,000017 \\
\hline IEAML5 & 0,39913 & 3 & 0,84975 & 52 & 8,1415 & 0,000154 \\
\hline IEAML6 & 0,91203 & 3 & 1,17279 & 52 & 13,4793 & 0,000001 \\
\hline IEAML7 & 0,30270 & 3 & 0,81783 & 52 & 6,4156 & 0,000884 \\
\hline AML_lndex & 65,91114 & 3 & 11,31345 & 52 & 100,9824 & 0,000000 \\
\hline IF11 & 1,64562 & 3 & 1,04035 & 52 & 27,4177 & 0,000000 \\
\hline IFI4 & 1,95379 & 3 & 1,23447 & 52 & 27,4333 & 0,000000 \\
\hline IFI5 & 1,46984 & 3 & 0,98638 & 52 & 25,8288 & 0,000000 \\
\hline IFI6 & 1,74064 & 3 & 1,17059 & 52 & 25,7742 & 0,000000 \\
\hline IFI7 & 2,49441 & 3 & 1,07424 & 52 & 40,2485 & 0,000000 \\
\hline IFI8 & 2,77915 & 3 & 1,17222 & 52 & 41,0948 & 0,000000 \\
\hline IF110 & 2,73368 & 3 & 1,21901 & 52 & 38,8707 & 0,000000 \\
\hline IF111 & 2,36172 & 3 & 1,05229 & 52 & 38,9021 & 0,000000 \\
\hline IF112 & 2,53960 & 3 & 1,19904 & 52 & 36,7123 & 0,000000 \\
\hline IF144 & 0,47575 & 3 & 0,56690 & 52 & 14,5464 & 0,000001 \\
\hline IF146 & 0,27827 & 3 & 0,28416 & 52 & 16,9741 & 0,000000 \\
\hline IF147 & 0,31215 & 3 & 0,40210 & 52 & 13,4561 & 0,000001 \\
\hline IF150 & 0,13378 & 3 & 0,36175 & 52 & 6,4102 & 0,000889 \\
\hline IF151 & 0,16720 & 3 & 0,47461 & 52 & 6,1062 & 0,001223 \\
\hline IF156 & 0,17610 & 3 & 0,80939 & 52 & 3,7713 & 0,015940 \\
\hline IF162 & 0,06333 & 3 & 0,15302 & 52 & 7,1743 & 0,000404 \\
\hline IF163 & 0,11843 & 3 & 0,23992 & 52 & 8,5562 & 0,000103 \\
\hline IF165 & 0,07730 & 3 & 0,16897 & 52 & 7,9293 & 0,000190 \\
\hline IF166 & 0,05485 & 3 & 0,16772 & 52 & 5,6683 & 0,001950 \\
\hline IF167 & 0,03577 & 3 & 0,18020 & 52 & 3,4403 & 0,023298 \\
\hline IF168 & 2,19865 & 3 & 1,30072 & 52 & 29,2990 & 0,000000 \\
\hline IF174 & 0,05032 & 3 & 0,13008 & 52 & 6,7048 & 0,000654 \\
\hline IF175 & 0,06182 & 3 & 0,15623 & 52 & 6,8589 & 0,000558 \\
\hline IF179 & 0,06140 & 3 & 0,13605 & 52 & 7,8227 & 0,000211 \\
\hline IF180 & 0,06333 & 3 & 0,15302 & 52 & 7,1743 & 0,000404 \\
\hline IF181 & 0,11843 & 3 & 0,23992 & 52 & 8,5562 & 0,000103 \\
\hline IF183 & 0,07730 & 3 & 0,16897 & 52 & 7,9293 & 0,000190 \\
\hline IF184 & 0,05485 & 3 & 0,16772 & 52 & 5,6683 & 0,001950 \\
\hline IF185 & 0,03577 & 3 & 0,18020 & 52 & 3,4403 & 0,023298 \\
\hline IF192 & 0,28079 & 3 & 0,65442 & 52 & 7,4372 & 0,000310 \\
\hline
\end{tabular}

Variables:

Indicators of AML policy effectiveness: IEAML1 - Money laundering and terrorist financing risks are understood and, where appropriate, actions co-ordinated domestically to combat money laundering and the financing of terrorism and proliferation; IEAML2 - International cooperation delivers appropriate information, financial intelligence, and evidence, and facilitates action against criminals and their assets; IEAML3 - Supervisors appropriately supervise, monitor and regulate financial institutions and DNFBPs for compliance with AMLCFT requirements commensurate with their risks; IEAMLA - Financial institutions and DNFBPs adequately apply AML/CFT preventive measures commensurate with their risks, and report suspicious transactions; IEAML5 - Legal persons and arrangements are prevented from misuse for money laundering or terrorist financing, and information on their beneficial ownership is available to competent authorities without impediments; IEAML6 - Financial intelligence and all other relevant information are appropriately used by competent authorities 
for money laundering and terrorist financing investigations; IEAML7 - Money laundering offences and activities are investigated, and offenders are prosecuted and subject to effective, proportionate and dissuasive sanctions;

AML Index - Basel AML Index Score;

Financial inclusion indicators: IFI1 - Account (\% age 15+), IFI4 - Account, income, poorest 40\% (\% ages 15+), IFI5 - Account, income, richest $60 \%$ (\% ages 15+), IFI6 - Account, rural (\% age 15+), IFI7 - Financial institution account (\% age 15+), IFI8 - Financial institution account, in labour force (\% age 15+), IFI10 - Financial institution account, income, poorest $40 \%$ (\% age 15+), IFI11 - Financial institution account, income, richest $60 \%$ (\% age 15+), IFI12 - Financial institution account, rural (\% age 15+), IFI44 - Saved at a financial institution (\% age 15+), IFI46 - Saved at a financial institution, out of labour force (\% age 15+), IFI47 - Saved at a financial institution, income, poorest $40 \%$ (\% age 15+), IFI50 - Saved using a savings club or a person outside the family (\% age 15+), IFI51 - Saved using a savings club or a person outside the family, in labour force (\% age 15+), IFI56 - Saved any money in the past year (\% age 15+), IFI62 Outstanding housing loan (\% age 15+), IFI63 - Outstanding housing loan, in labour force (\% age 15+), IFI65 - Outstanding housing loan, income, poorest $40 \%$ (\% age 15+), IFI66 - Outstanding housing loan, income, richest $60 \%$ (\% age 15+), IFI67 - Outstanding housing loan, rural (\% age 15+), IFI68 - Debit card ownership (\% age 15+), IFI74 - Borrowed for health or medical purposes (\% age $15+)$, IFI75 Borrowed for health or medical purposes, in labour force (\% age 15+), IFI79 - Borrowed for health or medical purposes, rural (\% age 15+), IFI80 - Borrowed to start, operate, or expand a farm or business (\% age 15+); IFI81 - Borrowed to start, operate, or expand a farm or business, in labour force (\% age 15+); IFI83 - Borrowed to start, operate, or expand a farm or business, income, poorest $40 \%$ (\% age 15+); IFI84 - Borrowed to start, operate, or expand a farm or business, income, richest $60 \%$ (\% age 15+); IFI85 - Borrowed to start, operate, or expand a farm or business, rural (\% age 15+); IFI92 - Borrowed from a financial institution or used a credit card (\% age $15+)$.

Source: own compilation

Grouping of countries into five clusters deteriorates the clustering quality: deterioration of intergroup, intragroup variances, Fisher's criterion and p-criterion in terms of financial inclusion indicators which showed share of people saving money in the past (IFI56), having outstanding housing loans (IFI62), in particular living rural (IFI67), and taking borrowing to start, operate, or expand a farm or business that living rural (IFI85). This fact indicates the inexpediency of further separation of clusters greater than four groups.

After estimating the amount of countries' clusters, the study consider implementing kmeans method (within agglomerative approach) to determine the composition of each selected cluster having substantiated the feasibility of allocating exactly four groups of countries in terms of reforming scenarios for the tactical and strategic monitoring system of transactions carried out by economic entities.

The composition of countries' clusters is presented as follows:

- the $1^{\text {st }}$ cluster: Burkina Faso, Democratic Republic of the Congo, Haiti, Cambodia, Madagascar, Mali, Mauritania, Nicaragua, Senegal, Sierra Leone, Uganda, Zimbabwe;

- the $2^{\text {nd }}$ cluster: Albania, Bangladesh, China, Honduras, Jordan, Kyrgyzstan; Mongolia, Malawi, Pakistan, Panama, Philippines, Serbia, Thailand, Tajikistan, Turkey, Tanzania, Zambia);

- the $3^{\text {rd }}$ cluster: Armenia, Botswana, Colombia, Dominican Republic, Egypt, Georgia, Ghana, Guatemala, Indonesia, Mexico, Peru, Ukraine;

- the $4^{\text {th }}$ cluster: Belarus, Chile, Costa Rica, Czech Republic, Greece, Hungary, Israel, Lithuania, Latvia, Malaysia, Russia, Singapore, Slovakia, Trinidad and Tobago, Uruguay.

Thus, structuring of countries by clusters in terms of AML scenarios to reform the system of tactical and strategic monitoring of transactions carried out by economic entities is presented as follows: $1^{\text {st }}$ cluster -12 countries; $2^{\text {nd }}$ cluster -17 countries; $3^{\text {rd }}$ cluster -12 countries; $4^{\text {th }}$ cluster - 15 countries.

We analyse the average values of these indicators based on the results of discrete statistics for countries' clustering within agglomerative methods (Table 4 ) to describe in details the AML scenarios for countries within each cluster based on the set of indicators (input variables) respectively for countries, in particular indicators of AML policy effectiveness, financial inclusion indicators and Basel AML Index Scores. 
Table 4. Countries' clustering according to the AML scenarios within average values of input indicators (variables)

\begin{tabular}{|c|c|c|c|c|}
\hline \multirow{2}{*}{ Variable } & \multicolumn{4}{|c|}{ Cluster means (Spreadsheet2.sta) } \\
\hline & Cluster 1 & Cluster 2 & Cluster 3 & Cluster 4 \\
\hline IEAML1 & 0,312500 & 0,500000 & 0,583333 & 0,600000 \\
\hline IEAML2 & 0,333333 & 0,588235 & 0,708333 & 0,700000 \\
\hline IEAML3 & 0,250000 & 0,455882 & 0,458333 & 0,516667 \\
\hline IEAML4 & 0,270833 & 0,426471 & 0,458333 & 0,500000 \\
\hline IEAML5 & 0,250000 & 0,323529 & 0,458333 & 0,450000 \\
\hline IEAML6 & 0,333333 & 0,470588 & 0,625000 & 0,666667 \\
\hline IEAML7 & 0,270833 & 0,382353 & 0,375000 & 0,483333 \\
\hline AML_lndex & 7,426667 & 5,920000 & 4,862500 & 4,514000 \\
\hline IF11 & 0,337446 & 0,522532 & 0,489937 & 0,814357 \\
\hline IFI4 & 0,242497 & 0,420686 & 0,361795 & 0,748030 \\
\hline IFI5 & 0,400543 & 0,590332 & 0,674811 & 0,858415 \\
\hline IFI6 & 0,300329 & 0,493919 & 0,449006 & 0,789537 \\
\hline IFI7 & 0,211068 & 0,481968 & 0,464896 & 0,813793 \\
\hline IFI8 & 0,249094 & 0,564085 & 0,534200 & 0,889418 \\
\hline IF110 & 0,126820 & 0,389790 & 0,339478 & 0,747520 \\
\hline IF111 & 0,267061 & 0,543354 & 0,547964 & 0,857817 \\
\hline IF112 & 0,182408 & 0,454845 & 0,425052 & 0,788749 \\
\hline IF144 & 0,076652 & 0,144831 & 0,123146 & 0,319303 \\
\hline IF146 & 0,041782 & 0,090253 & 0,072402 & 0,225211 \\
\hline IF147 & 0,042014 & 0,076220 & 0,069771 & 0,230539 \\
\hline IF150 & 0,202549 & 0,121294 & 0,128837 & 0,061103 \\
\hline IF151 & 0,229664 & 0,141292 & 0,153808 & 0,071952 \\
\hline IF156 & 0,495480 & 0,418379 & 0,407507 & 0,541751 \\
\hline IF162 & 0,064154 & 0,089376 & 0,076412 & 0,151375 \\
\hline IF163 & 0,072721 & 0,115629 & 0,099151 & 0,196244 \\
\hline IF165 & 0,042438 & 0,069611 & 0,055737 & 0,138592 \\
\hline IF166 & 0,078590 & 0,102533 & 0,090077 & 0,159865 \\
\hline IF167 & 0,058864 & 0,087046 & 0,080584 & 0,129128 \\
\hline IF168 & 0,104246 & 0,319702 & 0,285699 & 0,656709 \\
\hline IF174 & 0,143244 & 0,112216 & 0,117706 & 0,060267 \\
\hline IF175 & 0,155762 & 0,127657 & 0,136630 & 0,066971 \\
\hline IF179 & 0,144051 & 0,116088 & 0,125310 & 0,055656 \\
\hline IF180 & 0,064154 & 0,089376 & 0,076412 & 0,151375 \\
\hline IF181 & 0,072721 & 0,115629 & 0,099151 & 0,196244 \\
\hline IF183 & 0,042438 & 0,069611 & 0,055737 & 0,138592 \\
\hline IF184 & 0,078590 & 0,102533 & 0,090077 & 0,159865 \\
\hline IF185 & 0,058864 & 0,087046 & 0,080584 & 0,129128 \\
\hline IF192 & 0,100381 & 0,156675 & 0,185970 & 0,295062 \\
\hline
\end{tabular}

Source: own compilation

The AML scenarios within the peculiarities of the input variables and the analysis of their average values for the four countries' clusters presented in Table 4 are:

- the average values of indicators of the AML policy effectiveness in the countries from the $1^{\text {st }}$ cluster are the lowest and consistently increase from the $1^{\text {st }}$ to the $4^{\text {th }}$ cluster (as example, IEAML1 increases from 0,31 in the $1^{\text {st }}$ cluster up to 0,6 in the $4^{\text {th }}$ cluster), respectively, the AML policy effectiveness increases;

- the average values of the Basel AML Index Score in the countries of the 1st cluster are the highest and gradually decrease from the 1st to the 4th cluster (AML Index decreases from 7,42 in the $1^{\text {st }}$ cluster to 4,51 in the $4^{\text {th }}$ cluster), respectively ML / TF risks decrease;

- the average values of financial inclusion indicators in the countries of the 1 st cluster are the lowest and gradually increase from the 1st to the 4th cluster, respectively, the level of accessibility for the population in the use of financial products and services increases. 
Thus, from the above analysis of each cluster, we can summarize the following key features of AML scenarios peculiar to the countries in the relevant cluster:

- for the 1st cluster countries, the lowest values of financial inclusion indicators (average values from 0,04 till 0,495) are peculiar, accordingly - the lowest indicators of AML policy efficiency (average values from 0,25 till 0,33 ) and as a result - the highest ML/TL risks (average value of Basel AML Index Score is 7,43);

- in contrast to the AML scenarios for the countries of 1 st cluster, $4^{\text {th }}$ cluster countries are characterized by the highest financial inclusion indicators (average values from 0,05 till 0,889) among the population, the highest rates of AML measures effectiveness (average values from 0,45 till 0,7), and, accordingly, the lowest ML/TL risks (average value of Basel AML Index Score is 4,51);

- AML scenarios for the 2nd cluster countries consider relatively lower values of ML/TL risks (average value of Basel AML Index Score is 5,92), but not so crucially low values of financial inclusion (average values from 0,076 till 0,59) among the population and efficiency of implementation of AML policy (average values from 0,32 till 0,58) as for the countries of the 1st cluster.

- 3rd cluster countries are characterized by high financial inclusion indicators (average values from 0,055 till 0,67) among the population and high level of AML measures effectiveness (average values from 0,37 till 0,708) but their values are inferior to the 4th cluster, ML/TL risks within this cluster are relatively low (average value of Basel AML Index Score is 4,86).

Thus, the clustering of countries shows that the higher the financial inclusion for the population in the country is, the lower are the country-relevant ML/TF risks and the more effective the AML policy implementation by the state is.

After clustering countries according to the AML scenarios of reforming the system of tactical and strategic monitoring of transactions carried out by economic entities, we could formalize the portraits of countries' clusters with classification trees, using one-dimensional CART branching method.

Firstly, we will build portraits of countries' clusters considering simultaneous consideration of relevant financial inclusion indicators, ranking of countries on the Basel AML Index Score, and indicators of AML policy effectiveness at the country level. While using the with classification trees the calculated results shown in Table 5 include information about numbers of nodes, child nodes on the left and right branches, the number of objects in the classes, and the split variable condition.

Table 5. Countries' classification tree structure according to the AML scenarios

\begin{tabular}{cccccccccc}
\hline \multicolumn{7}{c}{$\begin{array}{l}\text { Tree Structure (Spreadsheet3 Class Tree.sta) } \\
\text { Child nodes, observed class n's, } \\
\text { predicted class, and split condition for each node }\end{array}$} \\
\cline { 2 - 11 } & $\begin{array}{c}\text { Left } \\
\text { branch }\end{array}$ & $\begin{array}{c}\text { Right } \\
\text { branch }\end{array}$ & $\begin{array}{c}\text { N in cls } \\
\text { Cluster1 }\end{array}$ & $\begin{array}{c}\text { N in cls } \\
\text { Cluster2 }\end{array}$ & $\begin{array}{c}\text { N in cls } \\
\text { Cluster3 }\end{array}$ & $\begin{array}{c}\text { N in cls } \\
\text { Cluster4 }\end{array}$ & $\begin{array}{c}\text { Predict. } \\
\text { class }\end{array}$ & $\begin{array}{c}\text { Split } \\
\text { constant }\end{array}$ & $\begin{array}{c}\text { Split } \\
\text { variable }\end{array}$ \\
\hline 1 & 2 & 3 & 24 & 34 & 24 & 30 & Cluster2 & $-5,50500$ & AML_Index \\
\hline 2 & 4 & 5 & 0 & 2 & 24 & 30 & Cluster4 & $-0,63385$ & IFI7 \\
\hline 3 & 6 & 7 & 24 & 32 & 0 & 0 & Cluster2 & $-6,72500$ & AML_Index \\
\hline 4 & & & 0 & 0 & 24 & 0 & Cluster3 & & \\
\hline 5 & 8 & 9 & 0 & 2 & 0 & 30 & Cluster4 & $-0,07730$ & IFI46 \\
\hline 6 & & & 0 & 32 & 0 & 0 & Cluster2 & & \\
\hline 7 & & & 24 & 0 & 0 & 0 & Cluster1 & & \\
\hline 8 & & 0 & 2 & 0 & 0 & Cluster2 & & \\
\hline 9 & & 0 & 0 & 0 & 30 & Cluster4 & & \\
\hline
\end{tabular}

AML Index - Basel AML Index Score;

Financial inclusion indicators: IFI7 - Financial institution account (\% age 15+), IFI46 - Saved at a financial institution, out of labor force (\% age $15+)$.

Source: own compilation 
Based on the analysis of results shown in Table 5, we can conclude that the left branch contains four nodes numbered 2, 4, 6, 8, the right - also four nodes numbered 3, 5, 7, 9. Based on the first line of Table it is seen that in the first top, 24 countries are classified to the $1^{\text {st }}$ cluster, 34 - to the $2^{\text {nd }}$ cluster, 24 - to the $3^{\text {rd }}$ cluster, 30 - to the $4^{\text {th }}$ cluster. Two branches come with vertices 2 and 3 from vertex 1. The value of Basel AML Index Score variable which takes value up to "5.50500" for the countries of a $4^{\text {th }}$ cluster and value over "5.50500" for the countries of the $2^{\text {nd }}$ cluster, is used to branch countries on vertices 2 and 3 the value. Further assignment of countries of the 4th cluster is based on the variable IFI7 (that shows the share of people who opened the account in financial institution), which must take a value of at least "0.63385", and the assignment of countries to $3^{\text {rd }}$ cluster otherwise. Further formalization of $2^{\text {nd }}$ and $4^{\text {th }}$ clusters requires the variable IFI46 (that shows the share of people excluded employed who make savings at financial institution), which is up to "0.07730" when selecting the countries of $2^{\text {nd }}$ cluster and $4^{\text {th }}$ cluster otherwise. If we consider the right branch of the $2^{\text {nd }}$ cluster countries to the $2^{\text {nd }}$ and $1^{\text {st }}$ cluster countries, the variable of Basel AML Index Score, which is up to "6.72500" for $2^{\text {nd }}$ cluster countries and is over "6.72500" for countries of the $1^{\text {st }}$ cluster is necessary to be assigning to the $1^{\text {st }}$ cluster countries.

Thus, in case of simultaneous consideration of relevant input indicators, in particular indicators of AML policy effectiveness, financial inclusion indicators and Basel AML Index Scores, it is possible to create the following cluster profiles:

- the $2^{\text {nd }}$ cluster countries consider the following necessary and sufficient conditions: Basel AML Index Score takes a value over 5.505 and up to 6.725, the variable IFI46 - up to 0.773;

- the $4^{\text {th }}$ cluster countries consider the following necessary and sufficient conditions: Basel AML Index Score takes the value up to 5.505, variable IFI7 - over 0.63385, variable IFI46 - over 0.773;

- the $3^{\text {rd }}$ cluster countries consider the following necessary and sufficient conditions: Basel AML Index Score takes the value up to 5.505, variable IFI7 - up to 0.63385;

- the $1^{\text {st }}$ cluster countries consider the following necessary and sufficient conditions: Basel AML Index Score takes the value over 6.725.

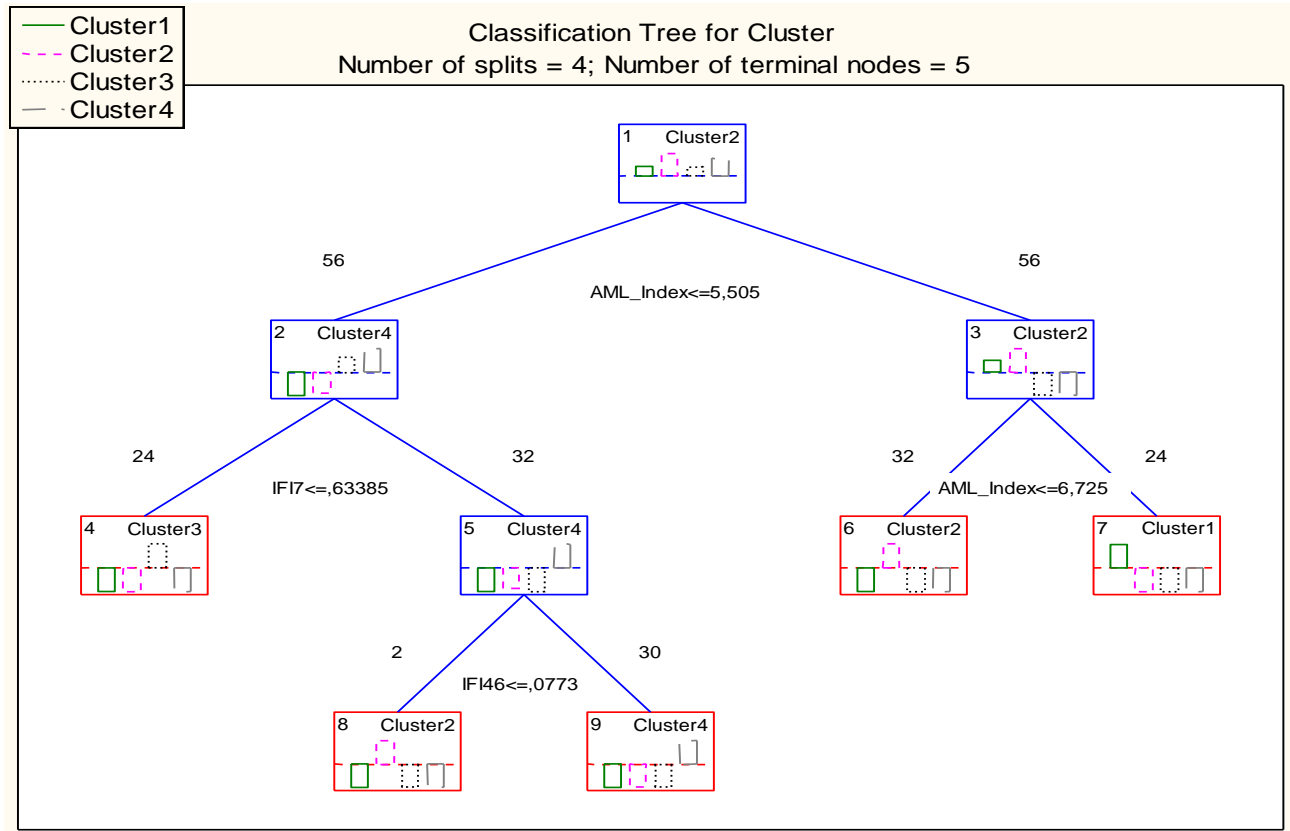

Split variables: AML Index - Basel AML Index Score; Financial inclusion indicators: IFI7 - Financial institution account (\% age 15+), IFI46 - Saved at a financial institution, out of labor force (\% age 15+).

Figure 1. Countries' classification tree graph according to the AML scenarios

Source: own compilation 
Thus, based on the graph of the countries' classification tree by the AML scenarios for reforming the system of tactical and strategic monitoring of transactions carried out by economic entities (Figure 1) and ranking indicators by the importance of impact on the countries' grouping (Figure 2), it is possible to draw a conclusion about the highest importance of the indicator Basel AML Index Score (100 points). Such financial inclusion indicators as availability of account within the share of people 15 years old (IFI11), share of people 15 years old who opened the account in financial institution (IFI7) and availability of account in financial institution within the share of people 15 years old living rural (IFI12) have 97,95 and 91 points of importance respectively.

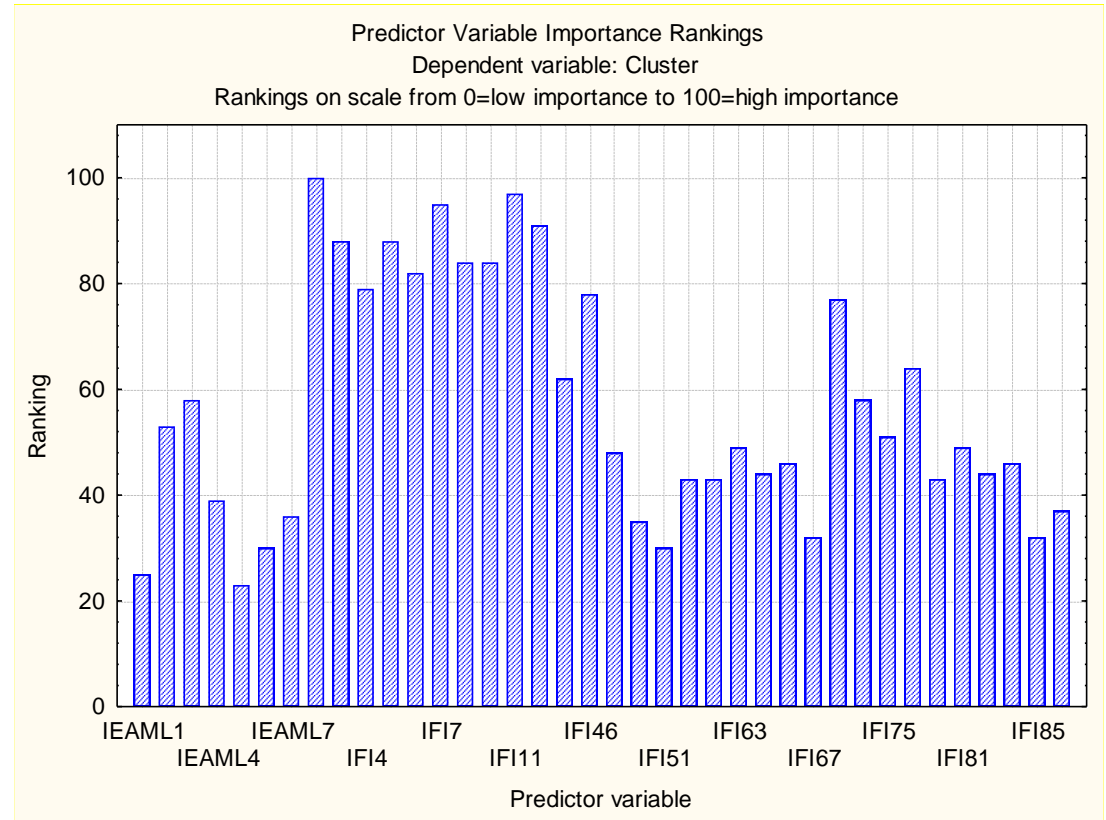

Predictor variables: IEAML1 - Money laundering and terrorist financing risks are understood and, where appropriate, actions co-ordinated domestically to combat money laundering and the financing of terrorism and proliferation;IEAML4 - Financial institutions and DNFBPs adequately apply AML/CFT preventive measures commensurate with their risks, and report suspicious transactions; IEAML7 - Money laundering offences and activities are investigated, and offenders are prosecuted and subject to effective, proportionate and dissuasive sanctions; IF14 - Account, income, poorest 40\% (\% ages 15+), IF17 - Financial institution account (\% age 15+), IF111 - Financial institution account, income, richest $60 \%$ (\% age 15+), IF146 - Saved at a financial institution, out of labor force (\% age $15+)$, IF151 - Saved using a savings club or a person outside the family, in labor force (\% age 15+), IF163 - Outstanding housing loan, in labor force (\% age 15+), IF167 - Outstanding housing loan, rural (\% age 15+), IF175 - Borrowed for health or medical purposes, in labor force (\% age 15+), IF181 - Borrowed to start, operate, or expand a farm or business, in labor force (\% age 15+), IF185 - Borrowed to start, operate, or expand a farm or business, rural (\% age $15+)$.

Figure 2. The ranking indicators by the importance of impact on the countries' grouping by the AML scenarios

Source: own compilation

After building portraits of countries' clusters considering simultaneous consideration of relevant financial inclusion indicators, ranking of countries on the Basel AML Index Score, and AML policy effectiveness indicators at the country level, we will continue the study within analyzing the separate consideration of the mentioned indicators.

According to the same algorithm, within constructing the portraits for countries' clusters using classification trees in the projection of the relevant indicators regarding the AML policy effectiveness at the country level, the following cluster profiles are:

- necessary and sufficient conditions to include countries to $1^{\text {st }}$ cluster are indicators of AML policy effectiveness namely IEAML2 and IEAML5 take values up to 0.375 , and IEAML1 - above 0.375; 
- necessary and sufficient conditions to include countries to $2^{\text {nd }}$ cluster are indicators of AML policy effectiveness namely IEAML1 and IEAML5 take the value up to 0.375; IEAML6 and IEAML4 - over 0.625 and 0.375 , respectively;

- necessary and sufficient conditions to include countries to $3^{\text {rd }}$ cluster are indicators of AML policy effectiveness namely IEAML4 and IEAML7 take values up to 0.75 ; and IEAML5 and IEAML7 - above 0.375 and 0.625 , respectively;

- necessary and sufficient conditions to include countries to $4^{\text {th }}$ cluster are indicators of AML policy effectiveness namely IEAML1 and IEAML5 take values up to 0.375 , and IEAML1, IEAML 7 and IEAML6 - above $0.375,0.375$ and 0.875 , respectively.

Within AML strategies implementation, the most important indicators are indicators of AML policy effectiveness that show: financial intelligence and other relevant information appropriately used by competent authorities for ML/TF investigations (IEAML6) - 100 points of importance; legal persons and arrangements prevented from misuse for ML/TF, and information on their beneficial ownership available to competent authorities without impediments (IEAML5) - 90 points of importance; money laundering offences and activities investigated, offenders are prosecuted and subject to effective, proportionate and dissuasive sanction (IEAML7) - 76 points of importance.

Within construction the portraits for countries' clusters using the classification trees in the projection of relevant financial inclusion indicators, the following cluster profiles are:

- a necessary and sufficient condition to include countries to $1^{\text {st }}$ cluster, is when financial inclusion indicator IFI85 takes values up to 0.0432, as well as IFI56 and IFI46 above 0.3704 and 0.0284 , respectively;

- a necessary and sufficient condition to include countries to $2^{\text {nd }}$ cluster is when financial inclusion indicators namely IFI56 and IFI92 take values up to 0.3704 and 0.1168 , and IFI85, IFI84, IFI47 - above 0.0432, 0.0917 and 0.1588 , respectively;

- a necessary and sufficient condition to include countries to $3^{\text {rd }}$ cluster is when the financial inclusion indicators IFI51 and IFI92 take values up to 0.1408 and 0.1812 , respectively;

- a necessary and sufficient condition to include countries to $4^{\text {th }}$ cluster is when the financial inclusion indicators IFI47 takes values up to 0.1588, and IFI8 and IFI56 - above 0.8495 and 0.5127 , respectively.

Tthe following financial inclusion indicators play the most important role (100 points) to form clusters in the projection of relevant indicators of financial inclusion : availability of account in financial institution among people over 15 years old (IFI7), in particular the richest (IFI11). The indicator showing the share of employed people with account in financial institution (IFI8) takes the second place of importance with 97 points, with 93 points indicator related to debit card ownership by population (IFI68) and with 91 points - indicator related to share of people living rural with account in financial institution (IFI12).

Turning to the construction the portraits for countries' clusters using the classification trees in the AML-Index projection, the following cluster profiles are:

- a necessary and sufficient condition to include countries to 1st cluster is when the Basel AML Index Score takes values above 6,725;

- a necessary and sufficient condition to include countries to 2 nd is when the Basel AML Index Score takes the value up to 6,725;

- a necessary and sufficient condition to include countries to 3rd cluster is when the Basel AML Index Score takes values above 5,065, up to 4,555;

- a necessary and sufficient condition to include countries to 4th cluster is when the Basel AML Index Score takes the value up to 4,435, above 5,34. 


\subsection{Digitization and COVID-19 impact on the AML scenarios}

Having constructed portraits of four selected clusters according to AML scenarios for reforming the system of tactical and strategic monitoring of transactions carried out by economic entities, it is necessary to implement the third stage - to determine how COVID-19 and digitization indicators affect scenarios. We re-group the countries into four clusters by expansion the list of financial inclusion indicators, AML effectiveness indicators and Basel AML Index Score with the indicators characterizing the impact of COVID-19 and digitization.

According to the variance analysis based on the intergroup, intragroup variances, and calculated values of Fisher's test and p-level, one can state that COVID-19 indicators and digitization changed the priority of financial inclusion indicators, AML efficiency indicators and Basel AML Index Score. Thus, absolutely all six considered indicators of COVID-19 and digitalization are statistically significant in allocating four clusters of countries around the world according to the AML scenarios. Such indicators as IEAML1, IEAML2, IEAML3, IEAML5, IEAML6 remained statistically significant among the AML policy effectiveness indicators. The Basel AML Index Score becomes statistically insignificant under the influence of COVID-19 and digitization. Among the indicators of financial inclusion IFI63, IFI65, IFI81, IFI83 became statistically significant.

In addition, the structure and redistribution of countries within the AML scenarios for reforming the system of tactical and strategic monitoring of transactions carried out by economic entities has undergone significant changes under the impact of COVID-19 and digitization:

- 1 st cluster - three countries (Colombia, Russia, Turkey); Ukraine);

- 2nd cluster - six countries (Indonesia, Mexico, Malaysia, Peru, Philippines,

- 3rd cluster - nine countries (Bangladesh, Chile, Czech Republic, Hungary, Israel, Jordan, Pakistan, Serbia, Thailand);

- 4th cluster - thirty-eight countries (Burkina Faso, Democratic Republic of the Congo, Haiti, Cambodia, Madagascar, Mali, Mauritania, Nicaragua, Senegal, Sierra Leone, Uganda, Zimbabwe, Albania, China, Honduras, Kyrgyzstan, Mongolia, Malawi, Panama, Tajikistan, Tanzania, Zambia, Armenia, Botswana, Dominican Republic, Egypt, Georgia, Ghana, Guatemala, Belarus, Costa Rica, Greece, Lithuania, Latvia, Singapore, Slovakia, Trinidad and Tobago, Uruguay.

Based on the results of constructing classification trees in the projection of COVID-19 and digitization indicators to conduct a more thorough study of the global triggers impact within implementing AML scenarios for reforming the system of tactical and strategic monitoring of transactions carried out by economic entities, the following conclusions could be formalized:

- necessary and sufficient conditions to include countries to $1^{\text {st }}$ cluster are when indicator related to the use of e-commerce products by the population before the pandemic (ICCOVID3) takes the value up to 0.0458, indicator of the impact of pandemic itself (ICCOVID2) - above 367.5, value of I-DESI (ICCOVID6) - up to 1.044, ICCOVID3 - above 0.1897 ;

- necessary and sufficient conditions to include countries to $2^{\text {nd }}$ cluster are when variable ICCOVID2 takes the value up to 367.5, ICCOVID2 - above 2486, ICCOVID3 - up to 0.1897 , indicator showing the COVID-19 cases (ICCOVID1) - up to 0.1408;

- necessary and sufficient conditions to include countries to $3^{\text {rd }}$ cluster are when variable ICCOVID2 takes the value up to 1307, ICCOVID2 - above 31886, ICCOVID3 - up to 1.0132 , ICCOVID3 - above 1.4298; 
- necessary and sufficient conditions to include countries to $4^{\text {th }}$ cluster are when variable ICCOVID6 takes value up to 0.0963, ICCOVID2 - above 1307, ICCOVID1 - above 0.1408 .

The most important indicators related to the pandemic and digitalization impact are ICCOVID3 and indicator related to current changes in e-commerce usage to purchase products normally bought in-store (ICCOVID5) - both have 100 points of importance, ICCOVID1 - 95 points.

According to the analysis of determining the impact of digitalization and COVID-19 on the AML policy, financial inclusion among population and ML/TF risks, the authors formalized possible AML-scenarios for reforming the tactical and strategic monitoring of transactions carried out by economic entities depending on the countries' adaptability (response) to the effects of digitalization and COVID-19 - respectively:

- AML-scenario of neutral adaptability, namely the country has not changed the cluster under the influence of digitalization and COVID-19 (Philippines, Belarus, Greece, Costa Rica);

- AML-scenario of slow adaptability, namely in terms of choosing the scenario under the influence of digitalization and COVID-19 the country has shifted by one position (one cluster) - for Turkey, Indonesia, Mexico, Peru, Ukraine;

- AML-scenario of moderately rapid adaptability, namely in terms of choosing the scenario under the influence of digitization and COVID-19 the country has shifted by two positions (two clusters) - typical for Colombia, China, Malaysia;

- AML-scenario of rapid adaptability, namely in terms of selecting the scenario under the influence of digitalization and COVID-19 the country has shifted by three positions (three clusters) - is typical for Russian Federation, Burkina Faso, Democratic Republic of the Congo.

It should be noted that the socio-economic development degree and the level of digitalization in the country will affect the country's choice of relevant AML-scenario for reforming tactical and strategic monitoring of transactions carried out by economic entities under the influence of digitalization and COVID-19.

\section{Conclusion}

The study highlights the issues and, based on the systematization of literature sources, justifies the need to consider the impact of today's global challenges, namely digitalization and the Covid-19 pandemic, on the changes of AML scenarios for reforming the system of tactical and strategic monitoring of economic transactions carried out by economic entities and based on good governance providing.

In the study, based on the FATF principles and policy, implementing the appropriate AML scenario suppose considering the chain of relationships as follows: the growth of financial inclusion among the population contributes to the effectiveness of AML measures while implementation the AML policy, that in turn minimizes economic and financial risks, particularly in the shadow sector.

The study focuses on formalizing AML scenarios for each country according to the country's cluster affiliation based on comprehensive system of indicators, involved indicators of AML policy effectiveness within countries, financial inclusion indicators and Basel AML Index, followed by determining the impact of digitalization and COVID-19 on the implementation of AML scenarios in terms of existing or new cluster (in case of transition to it). The choice of all indicators is justified by their role and significance for the practical solution of the goal set in the work. 
The study considers three stages of its implementation. The first stage involves the construction of a comprehensive set of indicators for the further calculations, included determining the priority financial inclusion indicators with the PCA-method. During the study the general set of financial inclusion indicators are analyzed. They characterize the following forms of financial services access to population: opening (availability) an account, in particular in a financial institution; the amount of savings; the amount of outstanding housing loan; loan to start a business - in terms of such criteria as income level, employment, living rural. The second stage of the study considers clustering the countries according to the AML scenarios based on analysis of financial inclusion indicators, indicators of AML policy effectiveness and directly Basel AML Index Scores within countries; formalizing the portraits of countries' clusters taking into account both simultaneous and separate consideration of relevant financial inclusion indicators, ranking of countries on the Basel AML Index Score, and indicators of AML policy effectiveness at the country level. While clustering the countries empirical research was implemented on the basis of agglomerative methods of minimum variance. Within that method the countries were divided into four groups (clusters) under the conditions of their similar characteristics within three groups of indicators that characterize: financial inclusion, efficiency of AML policy and Basel AML Index. The number of clusters was developed with variance analysis. The affiliation of countries to each cluster in the study was determined by k-means method (within using the agglomerative methods).

The conducted clustering of countries (12 countries classified into $1^{\text {st }}$ cluster, 17 - to $2^{\text {nd }}$ cluster, 12 - to $3^{\text {rd }}$ cluster, 15 - to $4^{\text {th }}$ cluster) shows that the higher the financial inclusion for the population in the country is, the more effective AML measures implemented by the state are, the lower the relevant ML / TF risks are.

The features of the AML scenarios within the peculiarities of the input variables and the analysis of their average values for the four countries' clusters confirmed the issues:

- the average values of indicators of the AML policy effectiveness in the $1^{\text {st }}$ cluster countries are the lowest and consistently increase from the $1^{\text {st }}$ to the $4^{\text {th }}$ cluster, respectively, the AML policy effectiveness increases;

- the average values of the Basel AML Index Score in the 1st cluster countries are the highest and gradually decrease from the 1st to the 4th cluster, respectively ML / TF risks decrease;

- the average values of financial inclusion indicators in the 1 st cluster countries are the lowest and gradually increase from the 1st to the 4th cluster, respectively, the accessibility level of the population in the use of financial products and services increases.

After clustering the countries, portraits of countries' clusters were formalized by onedimensional CART branching method within classification trees. The portraits of countries' clusters were formed using the classification tree method in terms of four projections: both simultaneous and separate consideration of relevant financial inclusion indicators, ranking of countries on the Basel AML Index Score, and indicators of AML policy effectiveness at the country level. The emphasis will be placed on each of the three groups of input indicators separately.

The third stage of the study considers determining the impact of digitalization and COVID-19 on the implementation of AML scenarios for countries in terms of existing or new cluster (in case of transition to it). The study of the COVID-19 and digitization effects on economic indicators, in terms of AML scenarios, in the study based on the analysis of the indicators of the pandemic impact, indicators characterizing the use of e-commerce products by the population during different periods of the pandemic, normalize scores of the I-DESI for each country. 
According to the variance analysis, the study substantiates that COVID-19 indicators and digitization influence the change in the priority of financial inclusion indicators, AML effectiveness indicators, and the AML index. All indicators considered in the paper, characterizing the impact of COVID-19 and digitization, are statistically significant when distinguishing four clusters of countries in the world according to AML scenarios. The structure and redistribution of countries within the clusters have changed significantly (1st cluster - 3 countries; 2nd cluster - 6 countries; 3rd cluster - 9 countries; 4th cluster - 38 countries) according to AML scenarios for reforming the system of tactical and strategic monitoring of transactions carried out by economic subjects.

The most important indicators while implementing AML-scenarios related to the pandemic and digitalization impact are the indicator demonstrating the use of e-commerce products by the population, the indicator showing the current changes in e-commerce usage to purchase products normally bought in-store, and the indicator showing the COVID-19 cases.

The results of empirical research let to determine the impact of digitalization and COVID-19 on the implementation of AML scenarios for countries within the current or new cluster (in case of transition to it). Depending on the countries' adaptability (response) to the effects of digitalization and COVID-19, the AML-scenario of neutral adaptability to the influence of digitalization and COVID-19, AML-scenario of slow adaptability, AML-scenario of moderately rapid adaptability, AML-scenario of rapid adaptability are defined.

\section{Acknowledgement}

The article was prepared based on the results of a research funded by the National Research Fund of Ukraine "Optimization and automation of financial monitoring processes to increase information security in Ukraine." (Registration number: 0120U104810).

\section{References}

Acemoglu, D., Johnson, S., Robinson. I., \& Thaicharoen, Y. (2004). Institutional causes. Macroeconomic symptoms: Volatility, crises and growth. Journal of Monetary Economics, 50(1), 49-123.

Adam, I., \& Fazekas, M. (2021). Are emerging technologies helping win the fight against corruption? A review of the state of evidence. Information Economics and Policy, 57, 1-14. https://doi.org/10.1016/j.infoecopol.2021.100950

Alam, Md. J., Jesmin, J., Faruk, M., \& Nur-Al-Ahad, Md. (2021). Development of E-banking in Bangladesh: A Survey Study. Financial Markets, Institutions and Risks, 5(2), 4251. doi.org/10.21272/fmir.5(2).42-51.2021

Al-Naser, M., \& Hamdan, A. (2021). The impact of public governance on the economic growth: Evidence from gulf cooperation council countries. Economics and Sociology, 14(2), 85-110. doi:10.14254/2071-789X.2021/14-2/5

Androniceanu, A. (2020). Major structural changes in the EU policies due to the problems and risks caused by COVID-19. Administratie si Management Public, 34, 137-149. doi.org/10.24818/amp/2020.34-08

Basel Institute on Governance (2021). Basel AML Index. Retrieved from: https://baselgovernance.org/basel-aml-index (20.01.2021).

Beyi, W. A. (2018). The trilogy of a digital communication between the real man, his digital individual and the market of the digital economy. SocioEconomic Challenges, 2(2), 66-74. doi:10.21272/sec.2(2).66-74.2018

Bilan, Y., Srovnalã-KovÃi, P., Streimikis, J., Lyeonov, S., Tiutiunyk, I., \& Humenna, Y. (2020a). From shadow economy to lower carbon intensity: Theory and evidence. 
International Journal of Global Environmental Issues, 19(1-3), 196-216. Retrieved from https://www.scopus.com/record/display.uri?eid=2-s2.085105821876\&origin=resultslist

Bilan, Y., Pimonenko, T., \& Starchenko, L. (2020b). Sustainable business models for innovation and success: Bibliometric analysis. Paper presented at the E3S Web of Conferences, , 159 doi:10.1051/e3sconf/20201590403

Boyko, A., \& Roienko, V. (2014). Risk assessment of using insurance companies in suspicious transactions. Economic Annals-XXI, 11-12, 73-76.

Brychko, M., Bilan, Y., Lyeonov, S., \& Mentel, G. (2021). Trust crisis in the financial sector and macroeconomic stability: a structural equation modeling approach. Economic $\begin{array}{lll}\text { Research-Ekonomska Istrazivanja, } & \text { 828-855. }\end{array}$ doi:10.1080/1331677X.2020.1804970

Chigrin, O., \& Pimonenko, T. (2014). The ways of corporate sector firms financing for sustainability of performance. International Journal of Ecology and Development, 29(3), 1-13.

Chmielecki, M. (2021). Leading intercultural virtual teams during the COVID-19 pandemic Research Results. Journal of Intercultural Management, 13(1), 69-87. doi.org/10.2478/joim-2021-0003

Civelek, M., Ključnikov, A., Kloudová, J., \& Vozňáková, I. (2021). Digital local currencies as an alternative digital payment method for businesses to overcome problems of COVID-19 pandemic. Polish journal of management studies, 23(2), 57-71. doi.org/10.17512/pjms.2021.23.2.04

Danarahmanto, P. A., Primiana, I., Azis, Y., \& Kaltum, U. (2020). The sustainable performance of the digital start-up company based on customer participation, innovation, and business model. Business: Theory and Practice, 21(1), 115-124. doi.org/10.3846/btp.2020.11053

Dementiev, E.V. (2021). Why Countries Differ Greatly in the Effects of COVID-19. Montenegrin Journal of Economics, 17(4), 55-63. doi.org/10.14254/18005845/2021.17-4.5

Didenko, I., Paucz-Olszewska, J., Lyeonov, S., Ostrowska-Dankiewicz, A., \& Ciekanowski, Z. (2020). Social safety and behavioral aspects of population's financial inclusion: A multicountry analysis. Journal of International Studies, 13(2), 347-359. doi:10.14254/2071-8330.2020/13-2/23

Didenko, I., \& Sidelnyk, N. (2021). Insurance innovations as a part of the financial inclusion. Business Ethics and Leadership, 5(1), 127-135. doi.org/10.21272/bel.5(1).127135.2021

Dr. Man Bahadur BK \& Bhandari, M.P. (2021). Microfinance institutions: instrumental for promoting financial inclusion. Financial Markets, Institutions and Risks, 5(2), 72-85. doi.org/10.21272/fmir.5(2).72-85.2021

FATF, (2013). Methodology for assessing technical compliance with the FATF recommendations and the effectiveness of AML/CFT systems. Retrieved from: Documents - Financial Action Task Force (FATF) (fatf-gafi.org) (20.01.2021).

Financial Action Task Force - FATF (2021). Retrieved from: https://www.fatf-gafi.org/ (21.01.2021).

Formankova, S., Trenz, O., Faldik, O., Kolomaznik, J., \& Vanek, P. (2018). The future of investing-sustainable and responsible investing. Marketing and Management of Innovations, 2, 94-102. doi.org/10.21272/mmi.2018.2-08

Gallo, P., Mihalcova, B., Vegsoova, O., Dzurov-Vargova, T \& Busova, N. (2019). Innovative Trends in Human Resources Management: Evidence for the Health Care System. 
Marketing and Management of Innovations, 2, 11-20. doi.org/10.21272/mmi.2019.201

Gasparėnienė, L., Remeikienè, R., \& Schneider, F. G. (2017). Concept, motives and channels of digital shadow economy: consumers' attitude. Journal of Business Economics and Management, 18(2), 273-287. doi.org/10.3846/16111699.2016.1214620

Hinrichs, G., \& Bundtzen, H. (2021). Impact of COVID-19 on personal insurance sales Evidence from Germany. Financial Markets, Institutions and Risks, 5(1), 80-86. doi.org/10.21272/fmir.5(1).80-86.2021

International Digital Economy and Society Index - I-DESI (2021). Retrieved from: https://eufordigital.eu/ru/library/digital-economy-and-society-index-desi-2020/ (20.01.2021).

International Monetary Fund - IMF (2021). IMF eLIBRARY. Retrieved from: https://www.elibrary.imf.org/view/journals/087/2020/008/article-A001-en.xml

Kadar, B., \& Reicher, R. Zs. (2020). Innovations in Health Care Management: the Effect of the Pandemic on the Labour Market Change. Marketing and Management of Innovations, 4, 120-130. doi.org/10.21272/mmi.2020.4-09

Kirichenko, L., Radivilova, T., \& Carlsson, A. (2017). Detecting cyber threats through social network analysis: short survey. SocioEconomic Challenges, 1(1), 20-34. doi: 10.21272/sec.2017.1-03

Kobushko, I., Tiutiunyk, I., Kobushko, I., Starinskyi, M., \& Zavalna, Z. (2021). The triadic approach to cash management: Communication, advocacy, and legal aspects. Estudios De Economia Aplicada, 39(7) doi:10.25115/eea.v39i7.5071

Kolosok, S., \& Jakubowska, A. (2020). Covid-19 and public health administration: trends and prospects. Health Economics and Management Review, 1(1), 69-75. doi.org/10.21272/hem.2020.1-06

Kozmenko, O., \& Roienko, V. (2013). Evaluation and use of indicators of insurance companies' investment activities. Investment Management and Financial Innovations, 10(3), 98-105. doi:10.21511/imfi.10(3).2013.01

Kuzmenko, O., Šuleř, P., Lyeonov, S., Judrupa, I., \& Boiko, A. (2020). Data mining and bifurcation analysis of the risk of money laundering with the involvement of financial institutions. Journal of International Studies, 13(3), 332-339. doi:10.14254/2071$8330.2020 / 13-3 / 22$

Lamberti, G., Lopez-Sintas, J., \& Sukphan, J. (2021). The social process of internet appropriation: Living in a digitally advanced country benefits less well-educated Europeans. Telecommunications Policy, 45 (1). Retrieved February 11, 2021, from https://www.sciencedirect.com/science/article/abs/pii/S0308596120301476

Leonov, S., Yarovenko, H., Boiko, A., \& Dotsenko, T. (2019). Information system for monitoring banking transactions related to money laundering. Paper presented at the CEUR Workshop Proceedings, 2422, 297-307. Retrieved from https://www.scopus.com/record/display.uri?eid=2-s2.085071081226\&origin=resultslist

Liu, N., Xu, Z., \& Skare, M. (2021). The research on COVID-19 and economy from 2019 to 2020: analysis from the perspective of bibliometrics. Oeconomia Copernicana, 12(2), 217-268. doi.org/10.24136/oc.2021.009

Lopez, B.S., García, D. I., \& Alcaide, A.V. (2019). Blockchain technology facing Socioeconomic Challenges. Promise versus Probability. SocioEconomic Challenges, 3(4), 13-24. doi:10.21272/sec.3(4).13-24.2019.

Lyeonov, S., \& Liuta, O. (2016). Actual problems of finance teaching in Ukraine in the postcrisis period. The financial crisis: Implications for research and teaching, 145-152. doi.org/10.1007/978-3-319-20588-5_07. 
Lyeonov, S., Żurakowska-Sawa, J., Kuzmenko, O., \& Koibichuk, V. (2020). Gravitational and intellectual data analysis to assess the money laundering risk of financial institutions. Journal of International Studies, 13(4), 259-272. doi:10.14254/20718330.2020/13-4/18

Lyulyov, O., Lyeonov, S., Tiutiunyk, I., \& Podgórska, J. (2021). The impact of tax gap on macroeconomic stability: Assessment using panel VEC approach. Journal of International Studies, 14(1), 139-152. doi:10.14254/2071-8330.2021/14-1/10

Małkowska, A., Urbaniec, M., \& Kosała, M. (2021). The impact of digital transformation on European countries: insights from a comparative analysis. Equilibrium. Quarterly Journal of Economics and Economic Policy, 16(2), 325-355. doi.org/10.24136/eq.2021.012

Matarazzo, M., Penco, L., Profumo, G., \& Roberto, Q. (2021). Digital transformation and customer value creation in Made in Italy SMEs: A dynamic capabilities perspective. Journal of Business Research, 123, 642-656. doi.org/10.1016/j.jbusres.2020.10.033

Maynard, G. (2021). What is Agglomeration in Economics? - Definition, Process, Theory \& Effects (2021). Retrieved from: https://study.com/academy/lesson/what-isagglomeration-in-economics-definition-process-theory-effects.html (03.02.2021).

Mishchuk, H., Bilan, S., Yurchyk, H., Akimova, L., \& Navickas, M. (2020). Impact of the shadow economy on social safety: The experience of Ukraine. Economics and Sociology, 13(2), 289-303. doi:10.14254/2071-789X.2020/13-2/19

Mishenina, H., Kirichenko, D., \& Puzemsky, V. (2021). COVID-19 impact on the company's development: a case of UNIT.City. Health Economics and Management Review, 2(2), 58-70. doi.org/10.21272/hem.2021.2-06

Oliinyk, V., Burdenko, I., Volynets, O., \& Yatsenko, V. (2019). Organized derivatives market and economic growth: Relationship and impact. Periodicals of Engineering and Natural Sciences, 7(2), 806-817. doi:10.21533/pen.v7i2.585

Pakhnenko, O., Rubanov, P., Hacar, D., \& Yatsenko, V. (2021). Digitalization of financial services in European countries: evaluation and comparative analysis. Journal of International Studies, 14(2), 267-282. doi:10.14254/2071-8330.2021/14-2/17

Pardal, P., Dias, R., Šuleř, P., Teixeira, N., \& Krulický, T. (2020). Integration in Central European capital markets in the context of the global COVID-19 pandemic. Equilibrium. Quarterly Journal of Economics and Economic Policy, 15(4), 627-650. doi.org/10.24136/eq.2020.027

Paskevicius, A., \& Keliuotyte-Staniuleniene, G. (2018). The evaluation of the impact of financial technologies innovations on CEECs capital markets. Marketing and Management of Innovations, 3, 241-252. https://doi.org/10.21272/mmi.2018.3-21

Petroye, O., Lyulyov, O., Lytvynchuk, I., Paida, Y., \& Pakhomov, V. (2020). Effects of information security and innovations on Country's image: Governance aspect. International Journal of Safety and Security Engineering, 10(4), 459-466. doi:10.18280/ijsse.100404

Petrushenko, Y., Kozarezenko, L., Glinska-Newes, A., Tokarenko, M., \& But, M. (2018). The opportunities of engaging FinTech companies into the system of crossborder money transfers in Ukraine. Investment Management and Financial Innovations, 15(4), 332344. https://doi.org/10.21511/imfi.15(4).2018.27

Petrushenko, Y., Onopriienko, K., Onopriienko, I., \& Onopriienko, V. (2021). Digital learning for adults in the context of education market development. Paper presented at the 11th International Conference on Advanced Computer Information Technologies, ACIT 2021. doi:10.1109/ACIT52158.2021.9548555 
Polinkevych, O., Khovrak, I., Trynchuk, V., Klapkiv, Y., Volynets, I. (2021). Business Risk Management in Times of Crises and Pandemics. Montenegrin Journal of Economics, 17(3), 99-110. https://doi.org/10.14254/1800-5845/2021.17-3.8

Principal Component Analysis (PCA, 2021). Retrieved from: https://sites.google.com/site/econometricsacademy/econometrics-models/principalcomponent-analysis (02.02.2021).

Przytuła, S., Strzelec, G., \& Krysińska-Kościańska, K. (2020). Re-vision of future trends in human resource management (HRM) after COVID-19. Journal of Intercultural Management, 12(4), 70-90. https://doi.org/10.2478/joim-2020-0052

Saraswati, B. D., Maski, G., Kaluge, D., \& Sakti, R. K. (2020). The effect of financial inclusion and financial technology on effectiveness of the Indonesian monetary policy. Business: Theory and Practice, 21(1), 230-243. https://doi.org/10.3846/btp.2020.10396

Sawangchai, A., Prasarnkarn, H., Kasuma, J., Polyakova, A. G., \& Qasim, S. (2020). Effects of COVID-19 on digital learning of entrepreneurs. Polish journal of management studies, 22(2), 502-517. https://doi.org/10.17512/pjms.2020.22.2.33

Setor, T.K., Senyo, P.K., Addo, A. (2021). Do digital payment transactions reduce corruption? Evidence from developing countries. Telematics and Informatics, 60. Retrieved February 12, 2021, from https://www.sciencedirect.com/science/article/abs/pii/S0736585321000162

Shpak, N., Kulyniak, I., Gvozd, M., Pyrog, O., Sroka, W. (2021). Shadow economy and its impact on the public administration: aspects of financial and economic security of the country's industry. Administratie si Management Public, 36, 81-101. https://doi.org/10.24818/amp/2021.36-05

Simovic, M. (2021). The impact of corruption on economic growth in the countries of Southeast Europe. Transformations in Business \& Economics, 20 (52). Retrieved February 10, 2021, from http://www.transformations.knf.vu.lt/52/article/thei

Smiianov, V. A., Lyulyov, O. V., Pimonenko, T. V., Andrushchenko, T. A., Sova, S., \& Grechkovskaya, N. V. (2020). The impact of the pandemic lockdown on air pollution, health and economic growth: system dynamics analysis. Wiadomosci Lekarskie, 73(11), 2332-2338.

Song, Y., \& Lu, Y. (2015). Decision tree methods: applications for classification and prediction. Shanghai Arch Psychiatry, 27 (2), 130-135. doi: 10.11919/j.issn.10020829.215044

Statista (2021). Retrieved from: https://www.statista.com/ (21.01.2021).

Stefan, G., Coca, O., Creanga, D.E., Mursa, G.C., Mihai, C. (2020). The Impact of the Crisis Generated by Covid-19 on the Population Concerns. A Comparative Study at the Level of the European Union. Transformations in Business \& Economics, 19(50B). Retrieved January 12, 2021, from http://www.transformations.knf.vu.lt/50b/article/thei

Stukalo, N., Lytvyn, M., Petrushenko, Y., \& Omelchenko, Y. (2020). The achievement of the country's sustainable development in the conditions of global threats. Paper presented at the E3S Web of Conferences, 211 doi:10.1051/e3sconf/202021101029

Stukalo, N. V., Lytvyn, M. V., Petrushenko, Y. M., Pylypenko, Y. I., \& Kolinets, L. B. (2021). The concept of sustainable development of Ukraine in the context of global threats. Naukovyi Visnyk Natsionalnoho Hirnychoho Universytetu, 3, 178-183. doi:10.33271/nvngu/2021-3/178

Syniavska, O., Dekhtyar, N., Deyneka, O., Zhukova, T., \& Syniavska, O. (2019). Modeling the process of counteracting fraud in e-banking. Paper presented at the CEUR Workshop Proceedings, Uktaine. 
The World Bank (2021). Indicators. Retrieved from: https://data.worldbank.org/indicator (21.01.2021).

Tiutiunyk I., Kostyuchenko N., Starinskyi M., \& Kobushko I. (2018). Methodical approach to the assessment of risks connected with the legalization of the proceeds of crime. Montenegrin Journal of Economics, 14(4), 23-43.

Tiutiunyk, I., Humenna, Yu., \& Flaumer, A. (2021a). Covid-19 impact on business sector activity in the EU countries: digital issues. Health Economics and Management Review, 2(1), 54-66. https://doi.org/10.21272/hem.2021.1-06

Tiutiunyk, I., Drabek, J., Antoniuk, N., Navickas, V., \& Rubanov, P. (2021b). The impact of digital transformation on macroeconomic stability: Evidence from EU countries, Journal of International Studies, 14(3), 220-234. https://doi.org/10.14254/20718330.2021/14-3/14

Tomcikova, L., Svetozarovova, N., \& Coculova, J. (2021). Challenges and Priorities in Talent Management During the Global Pandemic Caused by COVID-19. Marketing and Management of Innovations, 2, 94-103. https://doi.org/10.21272/mmi.2021.2-08

Trifu, A. (2020). Is it necessary a renewal of the theory of the firm based on pandemic realities? Business Ethics and Leadership, 4(2), 96-101. https://doi.org/10.21272/bel.4(2).96-101.2020.

Vala, K. (2019). Tree-Based Methods: classification. Retrieved from: https://towardsdatascience.com/tree-based-methods-classification-9729c5d14bc3 (05.02.2021).

World Health Organization (2021). Retrieved from: https://www.who.int/ (21.01.2021).

Yarovenko, H., Bilan, Y., Lyeonov, S., \& Mentel, G. (2021). Methodology for assessing the risk associated with information and knowledge loss management. Journal of Business Economics and Management, 22(2), 369-387. doi:10.3846/jbem.2021.13925

Zolkover, A., \& Terziev, V. (2020). The shadow economy: a bibliometric analysis. Business Ethics and Leadership, 4(3), 107-118. https://doi.org/10.21272/bel.4(3).107-118.2020 